\title{
ESPAÑOLISMOS Y MEXICANISMOS: UN ANÁLISIS CUANTITATIVO*
}

He tratado el problema de la variación léxica en investigaciones anteriores. Dentro de ese marco, me he referido también al concepto de españolismo desde el punto de vista cualitativo ${ }^{1}$ y sincrónico. He señalado, asimismo, los problemas ideológicos que subyacen en el planteamiento de los diccionarios de regionalismos de los países de América. Mis consideraciones, entre otros aspectos, se han enfocado hacia el hecho de que, si se parte de una propuesta sincrónica, no es adecuado comparar España - un país- con América - un continente, diecinueve

* Este artículo se presentó como ponencia en el I Congreso Internacional de Lexicografía Hispánica, La Coruña, septiembre de 2004, pero no se etregó para las Actas. La presente es una versión corregida y aumentada.

${ }^{1}$ Sobre la variación léxica, véase Raúl Ávila, "Variación léxica: connotación, denotación, autorregulación”, ALM, 35 (1997), 77-102. Me he referido a los españolismos en un art. de esta misma revista ("Españolismos y mexicanismos: hacia un diccionario internacional de la lengua española", $N R F H$, 46, 1998, 395-406). En relación con los diccionarios de regionalismos, véase mi "Diccionarios locales, nacionales, internacionales", RILI, 2003, núm. 1, 51-66 y “ ¿El fin de los diccionarios diferenciales? ¿El principio de los diccionarios integrales?”, RLex, 10 (2003-04), 7-20. Véase también, en relación con el concepto de regionalismo, Ambrosio Rabanales, Introducción al estudio del español de Chile, Instituto de Filología de la Universidad de Chile, Santiago, 1953; J. P. Rona, “¿Qué es un americanismo?”, en El simposio de México, enero de 1968. Actas, informes y comunicaciones, UNAM, México, 1969, pp. 135-148; y Luis Fernando Lara, Dimensiones de la lexicografía, El Colegio de México, México, 1990. No he sido el único que he propuesto el concepto de españolismo: véase J. M. Lope Blanch, "Americanismo frente a españolismo lingüísticos", NRFH, 42 (1995), 433-440, y J. Gossain, "La lengua española y los medios audiovisuales", Actas del Congreso de la lengua española, Sevilla, 7 al 10 de octubre de 1992, Instituto Cervantes, Madrid, 1994, pp. 165-171, quien menciona la opinión al respecto de B. Betancourt, ex presidente de Colombia. 
países. Eso equivaldría a comparar México - un país-con los diecinueve restantes.

Los países tienen fronteras políticas definidas dentro de las cuales, por cierto, se difunden y limitan un buen número de cambios lingüísticos, sobre todo los generados por las instituciones nacionales; y se promueve una política lingüística explícita o implícita. Son esas fronteras nacionales las que establecen vínculos de identidad lingüística. Las diferencias léxicas entre dos países se explican en buena medida por ese hecho. Este tipo de propuestas se presentan, por ejemplo, en relación con el inglés de EE.UU. y de Gran Bretaña, o el portugués de Brasil y de Portugal. Los diccionarios o vocabularios correspondientes se encuentran, incluso, en internet ${ }^{2}$.

He insistido en la comparación entre países o regiones bien delimitadas en relación con la variación lingüística ${ }^{3}$, y parece necesario hacerlo de nuevo, ya que aún se mantienen los criterios ideológicos a los que me he referido previamente ${ }^{4}$. Así, para evitar la comparación entre España y América el diccionario CLAVE (p. xi) ${ }^{5}$ utiliza la expresión eufemística español meridio-

${ }^{2}$ Véase, por ejemplo, para el inglés, Jeremy Sмiтh, The American BritishBritish American dictionary for English speaking people, 2004 (http://www.peak. org/ jeremy/dictionary, 8 de octubre); y para el portugués, MillôR FERnanDES, Dicionário português-brasileiro, 2004 (http://www.portcult.com/11.DICT1. htm, 19 de octubre). En este último se encuentran referencias a otros diccionarios del portugués lusitano vs. el brasileño.

${ }^{3}$ El planteamiento puede ser diferente cuando se compara el español de los medios orales de comunicación masiva. Si son de alcance internacional, puede proponerse otro tipo de clasificaciones a partir de las variantes, por ejemplo fónicas, y no de las regiones. Véase, al respecto, R. ÁviLA, "La pronunciación del español: medios de difusión masiva y norma culta", NRFH, 51 (2003), 57-79.

${ }^{4}$ Véase al respecto las consideraciones de L. F. LARA, "Por una redefinición de la lexicografía hispánica”, NRFH, 44 (1996), p. 359.

${ }^{5}$ En adelante, haré uso de las siguientes abreviaturas: ANAYA: ANAYA. Diccionario Anaya lengua española primaria, Anaya-Vox, Barcelona, 1997; CLAVE: Clave. Diccionario de uso del español actual, SM, Madrid, 1997 (se consultó también la versión electrónica en http://clave.librosvivos.net, 14 de junio de 2004); CREA: Corpus de referencia del español actual, Real Academia Española, Madrid (en http://www.rae.es, 29 de octubre de 2004); DIME: Raúl Ávila, con la colab. de Gerardo Aguilar, DIME. Diccionario inicial del español de México, 2ª ed., Trillas, México, 2004; DEA: Manuel Seco, Olimpia Andrés y Gabino Ramos, Diccionario del español actual, Aguilar, Madrid, 1999; DEUM: Diccionario del español usual en México, dir. de L. F. Lara, El Colegio de México, México, 1998; DRAE: Real Academia Española, Diccionario de la lengua española, 22aㅡ ed., Espasa, Madrid, 2001; DRAEL: Real Academia Españo- 
nal que, según se puede interpretar, abarca desde Andalucía hasta Tierra del Fuego: "El diccionario CLAVE otorga pleno reconocimiento a las dos grandes normas lingüísticas del español: la norma castellana (la del centro-norte peninsular), y la norma meridional (la del sur peninsular, Canarias e Hispanoamérica)". Y continúa CLAVE (p. xiii):

Existe en esta modalidad [la meridional] una gran variación léxica, aunque también se observa un buen número de coincidencias. Estas indudables semejanzas... nos autorizan a utilizar de manera genérica el rótulo de español meridional (también se le ha denominado español atlántico) para todo este complejo dialectal... Así hemos determinado el carácter general en casi todo el español meridional de voces como estampilla ('sello de correos'), cuadra ('manzana de casas'), friolento ('friolero') o agriparse ('comenzar a tener la gripe').

Por su parte, el DRAE también consigna estampilla como americanismo, y agriparse como usual en varios países americanos; define cuadra (ac. 8), más adecuadamente que el CLAVE, como "espacio de una calle comprendido entre dos esquinas; lado de una manzana", sin marca geográfica; y en friolento - sin marcaremite a friolero. En otro tipo de tratamiento, tanto en DRAE como en CLAVE se consigna papa ("del quechua papa", DRAE), que remite al vocablo preferido patata ("cruce de papay batata", $D R A E)$, de uso minoritario en la comunidad hispánica. Además, el DRAE incluye el españolismo piragüismo, voz que debería estar marcada, pero no canotaje, de uso general en América.

Es claro, por una parte, que resulta difícil precisar las zonas o los países en los que se usa una voz determinada. Por otra, si la gran mayoría de la población hispanohablante usa un vocablo alfa, y una minoría el beta, el término que debería estar marcado sería el beta. En los casos anteriores el vocablo marcado es el sinónimo que se usa en el español septentrional, que tiene como máximo unos 30 millones de hablantes, frente a 370 millones del meridional ${ }^{6}$, aproximadamente. Este sería el trata-

la, Diccionario de la lengua española, ed. electrónica, versión 1 de la segunda tirada, corr., de la 22a ed., Espasa, Madrid, 2003; EM: El Mundo (en http:/ / www. elmundo.es/diccionarios, 14 de junio de 2004).

${ }^{6}$ Para España consideré dentro del español meridional Extremadura, Andalucía y Canarias (cifras del Censo 2001 por Comunidad Autónoma y Provincia, del Instituto Nacional de Estadística, España, 2004, en www.ine. es/ine.base, 15 de junio de 2004). Si no se toman en cuenta las regiones 
miento en un diccionario que pretenda tener valor internacional, a partir de consideraciones de frecuencia - número de hablantes-y dispersión -número de países.

Esp. y Méx. en el DRAE

A lo anterior habría que añadir el tratamiento poco equilibrado que el $D R A E$ da a los regionalismos o, más específicamente, a los mexicanismos en relación con los españolismos. La versión electrónica de ese diccionario (DRAEL) permite, mediante una búsqueda de las abreviaturas, recopilar todas las voces -o incluso las acepciones de los vocablos- que se usan de manera exclusiva en diferentes países. De esta manera, se encuentran, con la marca geográfica Méx. (México) un total de 2434 voces; y con la marca Esp. (España), sólo 51. La suma de los dos conjuntos de vocablos es de 2485 (100\%), lo que da un porcentaje de $98 \%$ de mexicanismos y únicamente de $2 \%$ de españolismos, cifras que se antojan poco realistas.

Por otra parte, es necesario señalar que algunas de esas 51 voces (o acepciones) de España ${ }^{7}$ no son exclusivas de ese país, como es el caso de claxon, conducir (un vehículo), o IVA (impuesto al valor agregado) que se utilizan en todo México y en otros países hispanohablantes. Si los responsables del DRAEL (y del DRAE) hubieran consultado el Corpus de Referencia del Español Actual (CREA), formado por la Real Academia Española, habrían encontrado, por ejemplo, que claxon se usa no sólo en España y México, sino también en Cuba, Perú, Chile, Nicaragua, Puerto Rico, EE.UU., Venezuela y en "otros"; y que también hay concordancias de varios países para conducir (un vehículo). Sin embargo, aunque algunos de los considerados españolis-

con otra lengua materna (Galicia, País Vasco, Cataluña, Baleares, Valencia), el español septentrional se reduciría a unos 15 millones de hablantes.

${ }^{7}$ Las que permite recuperar el DRAEL son las siguientes, en orden alfabético: apartamento, apartamiento, bonobús, bonoloto, bote ${ }^{2}$, capitán, claxon, comisaría, conducir, cheli, caña, chachi $i^{1}$, chanchi, caldo, cuento ${ }^{1}$, cubata, droguería, duro, ra, gris, guay ${ }^{2}$, ganchito, grapo, hierba, interinidad, IVA [?], legal, madero, mir, nacionalidad, nicaragüeñismo, ordenador, película, piso, pastón ${ }^{2}$, pecero, pene$n e$, PNN, sudaca y tragaperras. Por supuesto, se consideran las acepciones españolas, pero aún así no todas las voces parecen exclusivas de España, y algunas resultan inesperadas, como IVA ("Impuesto al valor agregado"), que se usa en todos los países donde se aplica ese tipo de impuesto. 
mos no lo son, hay muchos otros vocablos exclusivos de España en comparación con México que no se consignan en el DRAEL, como mostraré más adelante.

\section{DiCCIONARIOS Y VOCABLOS}

Las razones antes expuestas me parecen suficientes para proponer una comparación léxica objetiva de los dos países, ahora desde el punto de vista cuantitativo. Por supuesto, esta clase de análisis debe sustentarse en corpora equiparables. Para esto basta tomar, por ejemplo, un texto español y un mexicano de extensión y fuentes equivalentes: libros, revistas, grabaciones, programas de televisión o de radio, entre otros. Sin embargo, este tipo de corpus no representa por sí mismo de manera suficiente el léxico de cada país, pues entre otros aspectos se limita, en buena medida, a un determinado registro. Tampoco sería adecuado comparar sólo los casos de variación, como los que se consignan en algunas investigaciones ${ }^{8}$, pues habría una sobrerrepresentación de las divergencias.

Frente a lo anterior, considero que se obtienen resultados más representativos si se comparan dos diccionarios equivalentes del español actual: uno de España y otro de México. La ventaja de esta comparación estriba en que los diccionarios construyen su nomenclatura a partir de diferentes fuentes y registros, por lo que representan más adecuadamente el léxico y su empleo. Además, si son del español actual, aseguran el uso real del vocabulario que incluyen.

En México se cuenta con dos diccionarios nacionales: el DEUM, concebido como general; y más recientemente, el $D I M E$, de tipo pedagógico. La nomenclatura del DEUM, sin embargo, tiene limitaciones por ser abierta: se inserta en una serie de diccionarios, en la cual el siguiente es una ampliación del anterior. Por eso - de acuerdo con los criterios de selección de la nomenclatura del DEUM - no es de extrañarse que falten allí algunos vocablos que podrían considerarse usuales en el español de México ${ }^{9}$ El DIME, en cambio, se concibió

${ }^{8}$ H. Ueda y T. TAKagaki, Varilex. Variación léxica del español en el mundo, Universidad de Tokio, 1993.

${ }^{9}$ Dentro de nuestra investigación encontramos, por ejemplo, los siguientes que están en el DIME pero no en el DEUM: empanizar, tapar, alcayata, enyesar, editory varios más. 
como un diccionario de nomenclatura cerrada. Su limitación, en todo caso, es su enfoque pedagógico, por lo que incluye únicamente los vocablos que utilizan o requieren los lectores mexicanos que cursan la educación básica.

En España se ha redactado un buen número de diccionarios, incluso de tipo pedagógico ${ }^{10}$. Dentro de este conjunto, y dado que se trataba de hacer una comparación con el DIME se decidió seleccionar el $A N A Y A$, también pedagógico. Este diccionario y el $D I M E$, además, tienen una cantidad parecida de entradas, en números aproximados: 12000 frente a 13000, respectivamente.

Para hacer la comparación de los dos diccionarios, seleccionamos aleatoriamente el $10 \%$ de las páginas de cada uno de ellos ${ }^{11}$. A continuación recogimos el total de vocablos de esas páginas. De esta manera se obtuvieron 1193 vocablos en ANAYA, y 1312 en DIME. Finalmente, para comparar el mismo número de vocablos en los dos diccionarios, eliminamos aleatoriamente de DIME los necesarios para quedarnos con 1193 voces.

\section{LOS REGIONALISMOS Y SU CLASIFICACIÓN}

Tras hacer las listas de los vocablos de ANAYA y de DIME, delimitamos dos conjuntos de formas: las de la muestra de ANAYA que aparecían también como entradas en DIME, y viceversa (Anexos 5 y 6); y las de la misma muestra de ANAYA que no se encontraron en DIME, y viceversa (Anexos 1 a 4). En este análisis no consideramos las voces del primer conjunto, a pesar de que podría haber diferencias en las acepciones ${ }^{12}$. Del segundo conjunto - el de los vocablos que estaban en $A N A Y A$ pero no

${ }^{10}$ H. Hernández, "La lexicografía escolar del español: desde sus orígenes hasta su consolidación”, RILI, 2003, núm. 1, 7-26.

${ }^{11}$ Para todo esto conté con la colaboración de Arturo Guzmán, investigador de proyecto de El Colegio de México. Le agradezco su valiosa ayuda y su acuciosidad para mantener un criterio congruente en el análisis de los españolismos y los mexicanismos.

12 Por ejemplo, desvelar en España es 'quitar el velo' (“desvelaron la estatua"). En cambio, en México significa 'trasnochar' ("El ruido lo desveló"). Véanse más ejemplos en R. ÁviLA, "Españolismos y mexicanismos: hacia un diccionario internacional de la lengua española". Aunque decidimos posponer este tipo de análisis en las formas idénticas, no lo eludimos en el estudio de las formas diferentes que recogimos en cada diccionario, como se puede ver más adelante, y en los Anexos. 
en DIME o al contrario- eliminamos los que no aparecían en alguno de los diccionarios por criterios que consideramos relacionados con la conformación de la nomenclatura (Anexos 3 y 4), como los gentilicios de España - cacereño, etc.- o los de México -guerrerense, por ejemplo-; o los regionalismos como chuparrosa ('colibrî'), que se incluye en DIME por razón de sus fuentes ${ }^{13}$, pero no es de uso general en México. Dentro del criterio de la formación de la nomenclatura también suprimimos las voces conocidas en los dos países ${ }^{14}$, pero aparentemente no usuales en el nivel escolar básico de uno de ellos, como cubertería y comparecer (en ANAYA, no en DIME, pero conocidos en México), aldaba y acaparar (en DIME, no en ANAYA, pero conocidos en España); o los tecnicismos ortodoncia (ANAYA) u oleaginoso (DIME), entre otros.

El análisis que hicimos a continuación se basó en el léxico remanente o diferencial (Anexos 1 y 2). En esta fase consideramos tanto las formas como las acepciones, de cada una, de los españolismos y los mexicanismos, para lo cual, además de los diccionarios muestreados, consultamos otras fuentes lexicográficas (sobre todo CLAVE, DEA, DEUM, DRAE), e interrogamos a varios informantes calificados, mexicanos y españoles. Tras esto, clasificamos los vocablos en los siguientes tipos ${ }^{15}$ :

a) Variantes connotativas. Corresponden a los vocablos de un país que tienen una voz equivalente en el otro ${ }^{16}$, o un hiperónimo. Son españolismos connotativos (ecn), por ejemplo, piragüismo, ceporro ${ }^{17}$ y arcén (muestra de ANAYA), que corresponden a los vocablos mexicanos canotaje, menso y acotamiento

13 La fuente primaria de DIME fue un conjunto de textos de niños de tercero a sexto de primaria de escuelas de todo México.

${ }^{14}$ Para España utilizamos sobre todo el DRAE y el CLAVE. Para México nos apoyamos en el DEUM y en la documentación del DEM (Diccionario del Español de México), que se conserva en El Colegio de México.

${ }_{15}$ Para los contextos y definiciones de los vocablos de la muestra, véase la Tabla 1.

16 Este tipo de variación (a vs. b), el más conocido, frecuentemente implica voces que están incluidas en subconjuntos semánticos diferentes (R. ÁvilA, "Variación léxica: connotación, denotación, autorregulación").

17 También se consideró el uso. Por eso ceporro (informal, ANAYA), equivale a menso (coloquial, DIME). Por otra parte, ceporro es un españolismo en sentido absoluto ya que, si se consulta el CREA, sólo se obtienen contextos (concordancias) para esta voz en textos de España. Lo mismo sucede con otras voces que consulté, como forofo y arcén. Llama la atención, de nuevo, que no tengan la marca Esp. en el DRAEL. 
$(D I M E)^{18}$. Son, en cambio, mexicanismos connotativos (mcn) refacción, apagador u olote (muestra de DIME), frente a los equivalentes españoles recambio, interruptor (ANAYA, CLAVE, DEA, $D R A E)$ y zuro (DEA, DRAE, donde, además, se remite al vocablo s. v. "olote").

aa) Dentro de las variantes connotativas consideramos también las de tipo morfológico o fonético (emf, mmf), vocablos que en uno u otro país presentan estas clases de variación, como los españolismos soja, cacahuete, amerizar o empanar (emf, muestra de ANAYA) frente a soya, cacahuate, amarizar o empanizar (mmf, DIME), o como los mexicanismos comelón y apachurrar (mmf, muestra de DIME), en contraste con comilón y espachurrar (ANAYA, CLAVE, DRAE).

b) Variantes denotativas. Son las voces que hacen referencia a algo que no existe en uno de los dos países, o no parece existir, de acuerdo con las fuentes consultadas. Es el caso de mexicanismos denotativos $(\mathrm{mdn})$ como alebrije, 'animal fantástico que se hace de cartón y después se pinta'; o guacamole, 'ensalada con aguacate, chile, cebolla y tomate'. Frente a los anteriores, son españolismos denotativos (edn) voces como centollo, 'marisco', que no se conoce en México; y minibasket, que no parece jugarse en México.

\section{Resultados}

Recuento de formas (Tabla 1)

En total se recogieron 50 españolismos y 67 mexicanismos desde el punto de vista de sus diferencias de forma. La diferencia porcentual entre españolismos $(4.2 \%)$ y mexicanismos $(5.6 \%)$ es de $1.4 \%$. Este dato corresponde, en números redondos, a un incremento del 33\% de mexicanismos en relación con los españolismos; o a un decremento del $25 \%$ de españolismos en relación con los mexicanismos. En otros términos, dado que se encontraron 50 españolismos y 67 mexicanismos, se puede decir que por cada españolismo hay 1.34 mexicanismos o que,

18 Cabe advertir que los equivalentes no se recogieron en la muestra. Los incluimos única y necesariamente con el propósito de hacer la comparación e ilustrar la clasificación. Por otra parte, ceporro y forofo son españolismos en sentido absoluto. 
en número redondos, por cada 5 españolismos aparecieron 7 mexicanismos. La muestra es suficientemente representativa, por lo que puede considerarse que los resultados son válidos y que, consecuentemente, la diferencia es significativa.

TABLA 1

Variantes formales

\begin{tabular}{lrrrrr}
\hline & Núm. & \multicolumn{1}{c}{$\%$} & & Núm. & \multicolumn{1}{c}{$\%$} \\
\hline Esp. & 50 & 4.2 & Mex. & 67 & 5.6 \\
Total voc. & 1193 & 100.0 & & 1193 & 100.0 \\
\hline
\end{tabular}

Recuento de acepciones y clases (Tablas 2 y 3 )

A los vocablos con una sola acepción se les atribuyó el sinónimo o hiperónimo español o mexicano correspondiente, de acuerdo con las fuentes y los informantes. De manera semejante, se compararon cada una de las acepciones de los vocablos que tenían dos o más, y se recogieron sólo las acepciones discrepantes, españolas con respecto a las mexicanas y al contrario. Por ejemplo, la primera acepción del vocablo delegación (incluida en DIME, pero no en ANAYA) coincidía con el uso español: "grupo de personas que representan a otras" (DIME, véanse, también, CLAVE, DEA, DRAE); pero las acepciones 2 y 3, usuales en México, discrepaban de las españolas: "Cada una de las zonas en las que se divide el Distrito Federal" (España distrito), y "Edificio donde trabajan los empleados de cada una de esas zonas" (¿España edificio de la junta de distrito?).

De acuerdo con las consideraciones anteriores, del total de 50 españolismos formales hubo 44 con una sola acepción, y 6 con 2 acepciones que no se consignaron en el diccionario mexicano: atufar, forofo, majo, montador, pancho (tan) y señorito (véase Anexo 1). En cuanto a los mexicanismos, del total de 67, fueron monosémicos 58 y polisémicos 9 . De estos últimos, hubo 5 con 2 acepciones: alzado, aventar, aventón, chotear y ocote; uno con 3: guaje, y dos con 4: chueco y corrido (Anexo 2).

La categoría gramatical más frecuente fue la de sustantivo, tanto en los españolismos (67.9\%) como en los mexicanismos $(70.4 \%)$. A continuación se presentaron, en el recuento de es- 
pañolismos, los adjetivos, los verbos y los adverbios. En el caso de los mexicanismos, tras los sustantivos aparecieron también los adjetivos y, finalmente, los verbos.

\section{TABLA 2}

Españolismos en ANAYA: acepciones y clases

\begin{tabular}{|c|c|c|c|c|c|c|c|c|c|}
\hline & $A c$. & Cat. gram. & $\%$ & ecn & $\%$ & emf & $\%$ & $e d n$ & $\%$ \\
\hline & 7 & adjetivo & 12.5 & 6 & 13.3 & 1 & 12.5 & 0 & 0 \\
\hline & 1 & adverbio & 1.8 & 1 & 2.2 & 0 & 0.0 & 0 & 0 \\
\hline & 2 & loc. adv. & 3.6 & 2 & 4.4 & 0 & 0.0 & 0 & 0 \\
\hline & 38 & sustantivo & 67.9 & 31 & 68.9 & 4 & 50.0 & 3 & 100 \\
\hline & 8 & verbo & 14.3 & 5 & 11.1 & 3 & 37.5 & 0 & 0 \\
\hline Parc. & & & & 45 & 100 & 8 & 100 & 3 & 100 \\
\hline Total & 56 & & 100 & 45 & 80.4 & 8 & 14.3 & 3 & 5.4 \\
\hline
\end{tabular}

En cuanto a las clases de regionalismos, los más abundantes fueron los connotativos que, junto con la subcategoría de morfofonológicos, representan el $94.7 \%$ de los españolismos, y el $84 \%$ de los mexicanismos. Complementariamente, los españolismos denotativos representan el 5.4\%; y los mexicanismos de la misma categoría, el $16 \%$ de las muestras respectivas. Los porcentajes ostentan una diferencia notable en cuanto a este último tipo de vocablos. Esto parece indicar que las realidades mexicanas son poco conocidas en España.

TABLA 3

Mexicanismos en DIME: acepciones y clases

\begin{tabular}{lclccccccc}
\hline & Ac. & Cat. gram. & $\%$ & $m c n$ & $\%$ & $m m f$ & $\%$ & $m d n$ & $\%$ \\
\hline & 14 & adjetivo & 17.3 & 12 & 19.0 & 2 & 40.0 & 0 & 0.0 \\
& 57 & sustantivo & 70.4 & 43 & 68.3 & 2 & 40.0 & 12 & 92.3 \\
& 10 & verbo & 12.3 & 8 & 12.7 & 1 & 20.0 & 1 & 7.7 \\
Parcial & & & & 63 & 100 & 5 & 100 & 13 & 100 \\
Total & 81 & & 100 & 63 & 77.8 & 5 & 6.2 & 13 & 16.0
\end{tabular}

\section{Conclusiones}

Los resultados estadísticos muestran que, de acuerdo con los diccionarios que se compararon, hay un número mayor de mexicanismos que de españolismos. Las razones pueden ser 
varias. Una de ellas es que la variante castellana -o quizá mejor, septentrional- sigue constituyendo el núcleo central de la lengua, y es la mejor descrita. Como consecuencia, tiene mayor prestigio y aceptabilidad, por lo menos en el plano léxico ${ }^{19}$. Esto supone un mayor conocimiento de los vocablos castellanos, sobre todo cultos, por ejemplo, por medio de las publicaciones de las empresas editoriales. Frente a esto, el léxico de los demás países o regiones es menos conocido a nivel internacional. El mayor número de mexicanismos denotativos y las voces polisémicas de este mismo país así lo constatan: México tiene una menor presencia en España que al contrario, y por eso se desconocen algunas de las nuevas realidades mexicanas.

Desde otro punto de vista, los datos estadísticos muestran que el diccionario mexicano es más inclusivo que el español. En efecto, el DIME, puesto que excluye el $4.2 \%$ de los vocablos españoles, incluye complementariamente el $95.6 \%$ de ese léxico. El ANAYA, en cambio, dado que excluye el $5.6 \%$ de mexicanismos, incluye sólo el $93.8 \%$ de las voces mexicanas.

En todo caso, las cifras que obtuvimos se ubican dentro del rango que considera Labov para la diferenciación lexicoestadística de dos dialectos a lo largo de 500 años, que es del $8 \% 20$. El español se implantó en América hace un poco más de cinco siglos, lo que parece indicar que los datos que surgen de nuestra comparación son razonablemente adecuados. El hecho de que nuestros porcentajes sean menores que los de Labov quizá se deba a las nuevas posibilidades comunicativas - del avión a la internet $-\mathrm{y}$ su posible influencia en la estandarización de la lengua.

La característica del léxico dialectal o nacional es que quienes lo usan lo sienten, literalmente, más natural que el aire que respiran. Descubrir un localismo requiere, por lo menos, viajar a otra región o a otro país o hablar con un forastero. No obstante, es necesario tomar conciencia del fenómeno, que algunos parecen ignorar. Todavía hay quienes se sorprenden o sonríen ante lo que no se dice en su aldea. El rechazo a las diferencias es una actitud superada en muchos órdenes. Las

19 Para las diferentes normas fonéticas y su aceptabilidad en el nivel internacional, véase, R. ÁvilA, "La pronunciación del español: medios de difusión masiva y norma culta”.

20 William Labov, Principles of linguistic change. Internal factors, Blackwell, Cambridge-Oxford, 1994, pp. 474-475. 
diferencias son enriquecedoras, sobre todo en esta época de estándares y de cesión de identidades.

De manera natural, las normas regionales conviven con las nacionales, y estas con las internacionales. Por supuesto, es fundamental mantener la unidad internacional de la lengua, pero no a partir de la imposición de una sola variante, sino con base en las normas nacionales, que se sustentarían, a su vez, en los usos regionales. En el caso del léxico, se requieren mayores investigaciones en cada uno de esos niveles. Por eso resultan necesarios los diccionarios integrales, pues son los únicos que pueden dar cuenta de las sutilezas de las relaciones léxicosemánticas.

Por otra parte, los escritores y los medios -la imprenta, la radio, la televisión, la red electrónica- podrían difundir y ayudarnos a ubicar los sonidos y los sentidos de cada uno de esos ámbitos. Así conoceríamos mejor nuestras palabras. Para ubicar adecuadamente el léxico que compartimos y el que nos diferencia, España, el único país que no parece haber planeado un diccionario de su léxico diferencial, debería ofrecernos, por lo menos, una lista más extensa de españolismos ${ }^{21}$.

RAúl ÁvILA

El Colegio de México

\section{ANEXOS}

OBSERVACIONES

1) Todas las acepciones incluidas en el Anexo 1. Españolismos son de ANAYA; y todas las que aparecen en el Anexo 2. Mexicanismos, de DIME.

2) En el caso de los españolismos, al final de cada contexto se indica la fuente.

3) Todos los contextos de los mexicanismos fueron tomados de DIME.

Siglas (véanse también las abreviaturas que ofrezco en nota 5):

$>\quad$ remite a

ac. acepción

am americanismo (usado en DRAE)

${ }^{21}$ He desarrollado esta proposición en varios artículos. El más reciente es " ¿El fin de los diccionarios diferenciales? ¿El principio de los diccionarios integrales?". 


$\begin{array}{ll}\text { aj } & \text { adjetivo } \\ \text { av } & \text { adverbio } \\ \text { DEMD } & \text { Diccionario del Español de México: Documentación. } \\ \text { ecn } & \text { españolismo connotativo } \\ \text { edn } & \text { españolismo denotativo } \\ \text { emf } & \text { españolismo morfofonético } \\ \mathrm{f} & \text { femenino } \\ \text { loc adv } & \text { locución adverbial } \\ \text { m } & \text { masculino } \\ \text { mcn } & \text { mexicanismo connotativo } \\ \text { mdn } & \text { mexicanismo denotativo } \\ \text { mmf } & \text { mexicanismo morfofonético } \\ \text { mrd } & \text { español meridional (usado en CLAVE) } \\ \mathrm{N} & \text { no } \\ \text { NIA pcn } & \text { no incluido en } A N A Y A \text { por criterio de nomenclatura } \\ \text { NID pcn } & \text { no incluido en DIME por criterio de nomenclatura } \\ \text { pl } & \text { plural } \\ \text { pn } & \text { pronominal } \\ \text { S } & \text { sí } \\ \text { st } & \text { sustantivo } \\ \text { vb } & \text { verbo }\end{array}$

\section{ANEXO 1}

\section{ESPAÑOLISMOS}

ambulatorio st m Clasificación: ecn Equivalente: clínica (DIME)

DRAE: $\mathrm{S}$ ac. 3 > dispensario CLAVE: $\mathrm{S}$ DEA: $\mathrm{S}$ ac. 1

Acepción: "Establecimiento sanitario donde se pasa consulta, pero sin camas para ingresar enfermos".

Contexto: "En este ambulatorio hay médicos de casi todas las especialidades" (CLAVE).

americana st $\mathrm{f}$ Clasificación: ecn Equivalente: saco, chaqueta (DIME)

DRAE: S sv americano ac. 5 CLAVE: S sv americano ac. 2

$D E A: \mathrm{S}$ sv americano ac. 11

Acepción: "Chaqueta recta con mangas, solapa y botones que llega hasta más abajo de la cadera y suele tener bolsillos en el exterior".

Contexto: "La americana es una prenda de vestir que actualmente usan hombres y mujeres" (CLAVE).

amerizar vb Clasificación: emf DRAE: $\mathrm{S}$

Equivalente: amarizar (NID pcn; DEUM) CLAVE: S DEA: $\mathrm{S}$

Acepción: "Descender una nave aérea y posarse sobre la superficie del agua".

Contexto: "El hidroavión amerizóen mitad del océano para rescatar a los náufragos" (CLAVE) 
aposta av Clasificación: ecn

Equivalente: adrede (DIME)

DRAE: $\mathrm{S}>$ adrede

CLAVE: S

DEA: $\mathrm{S}$

Acepción: "Se usa para expresar que una cosa se hace a propósito, teniendo la voluntad y la intención de hacerla".

Contexto: “¡Cómo te iba a pisar aposta, malpensada!” (CLAVE).

arcén st m Clasificación: ecn

Equivalente: acotamiento (DIME)

DRAE: S ac. 2

CLAVE: S

DEA: $\mathrm{S}$ ac. 1

Acepción: "Parte estrecha que hay en los lados de la carretera para que circulen personas a pie o en vehículos sin motor".

Contexto: "Detuvo el coche en el arcén para cambiar la rueda pinchada" (CLAVE).

archivador st m Clasificación: emf

Equivalente: archivero [mueble] (DIME), carpeta $(D I M E)$

DRAE: S ac. 2 y 3

CLAVE: $\mathrm{S}$ ac. 2 y 3

DEA: S

Acepción: "Carpeta, caja o mueble que sirve para guardar papeles o documentos de un modo ordenado y por separado".

Contexto: "El médico tiene en su consulta un archivador con cajones con las fichas de todos los pacientes" (CLAVE), "Los apuntes de clase los tengo en un archivador, clasificados por asignaturas" (CLAVE).

atufar ac. 1 vb Clasificación: ecn Equivalente: apestar(DIME)

$$
\text { DRAE: } \mathrm{S} \text { ac. } 4>\text { heder CLAVE: } \mathrm{S} \text { ac. } 1
$$

DEA: $\mathrm{S}$ ac. 4

Acepción: "Oler muy mal, como una bolsa de basura".

Contexto: “Estas zapatillas atufan, qué asco!” (CLAVE).

atufar ac. 2 vb Clasificación: ecn Equivalente: apestar(DIME)
DRAE: S ac. 1
CLAVE: S ac. 2
DEA: $\mathrm{S}$ ac. 1

Acepción: "Hacer que la respiración sea difícil o desagradable por el humo o un olor intenso".

Contexto: "Abre la ventana, que ese puro atufa" (ANAYA).

butifarra stf Clasificación: ecn Equivalente: longaniza (DIME)
DRAE: S
CLAVE: S
$D E A: \mathrm{S}$ ac. 1

Acepción: "Salchicha larga y gruesa, hecha de carne de cerdo picada, que se come frita o asada".

Contexto: "La butifarra es típica de Cataluña" (CLAVE).

cacahuete st m Clasificación: emf Equivalente: cacahuate (DIME)
DRAE: $\mathrm{S}$ ac. 2
CLAVE: $\mathrm{S}$ ac. 2
$D E A: \mathrm{S}$

Acepción: "Fruto del cacahuete que, cuando está maduro, pasa a ser un fruto seco en forma de vaina alargada, de color beige, que contiene varias semillas".

Contexto: "El cacahuete es una planta de origen americano" (CLAVE). 
cachas aj,stmf Clasificación: ecn Equivalente: mamado (NID pcn; DRAE: S CLAVE: S DEA: S

Acepción: "Se dice de la persona que está muy fuerte y tiene los músculos muy desarrollados... Es una palabra informal".

Contexto: "Desde que va al gimnasio está muy cachas" (ANAYA), "Salgo con un $c a$ chas que conocí en el gimnasio" (CLAVE).

cachondeo st m Clasificación: ecn Equivalente: cotorreo (DIME, uso coloquial) DRAE: Sac. 1 CLAVE:S ac. 1 DEA: $\mathrm{S}$ ac. 1

Acepción: "Acción o palabras con las que nos reímos de una persona o una cosa; se dice que la situación en la que alguien hace o dice algo para reírse de otros también es un cachondeo. Es una palabra informal".

Contexto: "Ya está bien de cachondeo, no os metáis más con él" (EM).

cegato ajyst Clasificación: emf Equivalente: cegatón (DIME, uso coloquial) DRAE: S CLAVE: S DEA: S

Acepción: "Se dice de la persona que no ve bien o que no ve bien de lejos. Es una palabra informal".

Contexto: "Está totalmente cegata porque saludó a una farola creyendo que era una persona" (CLAVE).

centollo st m Clasificación: edn $\quad$ Equivalente:DRAE: S CLAVE: $\mathrm{S} \quad$ DEA: $\mathrm{S}>$ centolla

Acepción: "Animal crustáceo marino con el cuerpo cubierto por una concha gruesa, rugosa y que tiene pelos y espinas".

Contexto: "El centollo es el marisco que más me gusta" (CLAVE).

ceporro aj, st Clasificación: ecn Equivalente: menso (DIME, uso coloquial) DRAE: S ac. 2 CLAVE: Sac. $1 \quad$ DEA: $\mathrm{S}$ ac. 1

Acepción: "Que es poco inteligente y tiene poca capacidad para aprender. Es una palabra informal".

Contexto: "Se queja de que sus alumnos son unos ceporrosy no se enteran de nada" (CLAVE).

cubata stf Clasificación: ecn $\quad$ Equivalente: cuba > cubalibre (DIME)

DRAE: $\mathrm{S}>$ cubalibre CLAVE: $\mathrm{S}$ DEA: $\mathrm{S}$

Acepción: "Cubalibre. Es una palabra informal". ["Bebida alcohólica compuesta por un refresco de cola mezclado con ron o con otro tipo de licor"].

Contexto: "Está borracho porque se ha tomado varias cubatas" (CLAVE).

despachurrar vb Clasificación: emf Equivalente: apachurrar (DIME) DRAE: $\mathrm{S}$ ac. $1 \quad$ CLAVE: $\mathrm{S}>$ espachurrar DEA: $\mathrm{S}$

Acepción: "Hacer que se estropee o salga el contenido de una cosa aplastándola o apretándola fuerte... Es una palabra informal".

Contexto: "Si una tarta se cae al suelo se despachurra" (ANAYA). 
empanadilla st $\mathrm{f}$ Clasificación: emf Equivalente: empanada (DIME) DRAE: S CLAVE: $\mathrm{S}$ DEA: $\mathrm{S}$

Acepción: "Pastel pequeño y salado, hecho con una lámina redonda de masa de harina que se dobla por la mitad; va relleno de varios ingredientes y se fríe en abundante aceite".

Contexto: "De segundo, tomaremos empanadillas de bonito" (CLAVE).

empanar vb Clasificación: emf Equivalente: empanizar (DIME)
DRAE: S ac. 2
CLAVE: S
$D E A: \mathrm{S}$

Acepción: "Cubrir un alimento con pan rallado antes de freírlo".

Contexto: "Para empanar los filetes, primero tienes que pasarlos por el batido de huevo y después untarlos en pan rallado" (CLAVE).

empastar vb Clasificación: ecn

Equivalente: tapar (DIME, acepción 5) DRAE: S ac. 3

CLAVE: S ac. 1

DEA: S ac. 2

Acepción: "Poner una pasta especial en los agujeros de las muelas y dientes que tienen caries".

Contexto: "Si la muela está picada, te la tendrás que empastar" (CLAVE).

escarpia st $\mathrm{f}$ Clasificación: ecn

DRAE: S

Equivalente: alcayata (DIME)

Acepción: "Clavo que en el extremo opuesto a la punta está doblado en ángulo recto y que se utiliza para colgar cosas en una pared".

Contexto: "Pon dos escarpias en la pared para colgar el cuadro" (CLAVE).

escayola st $\mathrm{f}$ Clasificación: ecn

Equivalente: yeso (DIME, DEUM)

DRAE: S ac. 1

CLAVE: $\mathrm{S}$ ac. 2

DEA: $\mathrm{S}$ ac. 1

Acepción: "Masa formada por yeso y agua que es fácil de modelar, y que cuando se seca se pone dura".

Contexto: "Me fracturé el brazo y me pusieron una escayola" (CLAVE).

escayolar vb Clasificación: ecn Equivalente: enyesar (DIME)
DRAE: S
CLAVE: S
$D E A: \mathrm{S}$ ac. 1

Acepción: "Envolver con escayola una parte del cuerpo que está rota para mantenerla inmóvil y ayudar a que se cure".

Contexto: "Me escayolaron una pierna y para andar tengo que apoyarme en unos bastones" (CLAVE).

forofo ac. 1 st Clasificación: ecn

Equivalente: fanático, fan, seguidor (DIME) DRAE: $\mathrm{S}>$ hincha

CLAVE: S

$D E A: \mathrm{S}$

Acepción: "Persona que sigue con pasión a un equipo deportivo".

Contexto: "Los forofos gritan mucho en el campo" (ANAYA).

forofo ac. 2 st Clasificación: ecn Equivalente: aficionado (DIME)

DRAE: $\mathrm{S}$ forma, N ac. CLAVE: $\mathrm{S}$ forma, $\mathrm{N}$ ac. DEA: $\mathrm{S}$

Acepción: "Persona a la que le gusta mucho algo".

Contexto: "Es forofa del sol" (ANAYA). 
jara st $\mathrm{f}$ Clasificación: edn $\quad$ Equivalente:DRAE: S CLAVE: $\mathrm{S}$ DEA: $\mathrm{S}$

Acepción: "Arbusto de hojas alargadas, aromáticas y pegajosas, con flores blancas, rosas o amarillas".

Contexto: "El aroma de la jara es muy agradable" (EM).

litrona st $\mathrm{f}$ Clasificación: ecn $\quad$ Equivalente: caguama (NID pcn; DEMD) DRAE: S CLAVE: S DEA: S

Acepción: "Botella de cerveza de un litro. Es una palabra informal".

Contexto: "Llevaron litronas, refrescos y patatas fritas para la fiesta" (CLAVE).

majara aj, st m f Clasificación: ecn

Equivalente: chiflado (DIME

[uso coloquial])

DRAE: $\mathrm{S}>$ majareta CLAVE: $\mathrm{S}>$ majareta $\quad$ DEA: $\mathrm{S}>$ majareta

Acepción: "Se dice de la persona que actúa de un modo poco responsable o imprudente. Es una palabra informal".

Contexto: "Para hacer semejante locura hay que estar majara perdido" (CLAVE).

majareta aj, st $\mathrm{m} \mathrm{f}$ Clasificación: ecn

Equivalente: chiflado (DIME

[uso coloquial])

DRAE: $\mathrm{S} \quad$ CLAVE: $\mathrm{S}$

DEA: S

Acepción: "Majara... Es una palabra informal".

Contexto: "¿Te crees que estoy majareta? No pienso dejarte mi bicicleta nueva para que hagas el bestia" (ANAYA).

majo ac. 1 aj Clasificación: ecn Equivalente: chido (DIME, uso popular) DRAE: $\mathrm{S}$ ac. 1 (coloquial) CLAVE: $\mathrm{S}$ forma, $\mathrm{N}$ ac $\quad$ DEA: $\mathrm{S}$ ac. 1

Acepción: "Se dice de la persona que es muy amable, simpática y agradable en el trato".

majo ac. 2 aj Clasificación: ecn Equivalente: chido (DIME, uso popular) DRAE: $\mathrm{S}$ ac. 2 (coloquial) CLAVE: $\mathrm{S}$ ac. 1 (coloquial) DEA: $\mathrm{S}$ ac. 2

Acepción: "Que es bonito o útil aunque no sea lujoso ni muy grande".

Contexto: "Se ha comprado un coche muy majo" (ANAYA), "Mi casa es pequeña pero muy maja" (CLAVE).

majorette st $\mathrm{f}$ Clasificación: ecn

Equivalente: bastonera (NID pcn;

DEMD, informantes)

DRAE: S CLAVE: S

DEA: $\quad \mathrm{S}$

Acepción: "Niña o mujer joven que marcha delante de una banda de música en un desfile. Las majorettes llevan un uniforme y un bastón que lanzan al aire y que recogen a lo largo de la marcha. Se pronuncia: "mayoret"

Contexto: "El desfile iba precedido por un grupo de majorettes" (CLAVE). 
manillar st m Clasificación: ecn DRAE: S

Equivalente: manubrio (DIME)

Acepción: "Pieza de una bicicleta o de una motocicleta que esta formada por una barra unida a la rueda delantera y que sirve para hacer girar el vehículo".

Contexto: "He colocado un timbre en el manillar de la bici" (CLAVE).

minibasket st m Clasificación: edn Equivalente:

DRAE: N CLAVE: $\mathrm{S}$

DEA: S [minibásket $]$

Acepción: "Baloncesto que se juega en una cancha más pequeña".

Contexto: "Empezó jugando a minibasket en el colegio y hoy es pívot de la selección nacional" (CLAVE).

monopatín st m Clasificación: ecn Equivalente: patineta (DIME)
DRAE: S
CLAVE: S
DEA: S

Acepción: "Objeto formado por una superficie plana con ruedas debajo que permite ponerse de pie sobre él y patinar sobre una superficie lisa y dura".

Contexto: "Bajamos la cuesta en monopatín y luego la subimos con él bajo el brazo" (CLAVE).

montador ac. 1 st Clasificación: ecn Equivalente: armador*
DRAE: S ac. 2
CLAVE: S ac. 1
DEA: S

Acepción: "Persona que se dedica a montar máquinas o aparatos en una fábrica".

Contexto: "Mi hermano es montador de electrodomésticos" (CLAVE).

montador ac. 2 st Clasificación: ecn Equivalente: editor (DIME)
DRAE: S ac. 3
CLAVE: S ac. 2
DEA: S

Acepción: "Persona que se dedica a montar películas de cine o programas de radio y televisión".

Contexto: "Ese director de cine siempre trabaja con la misma montadora" (CLAVE).

mullir vb Clasificación: ecn $\quad$ Equivalente: ablandar (DIME)
DRAE: S ac. 1
CLAVE: S ac. 1
DEA: $\mathrm{S}$ ac. 1

Acepción: "Hacer que una cosa apretada se quede blanda y esponjosa, generalmente dándole algunos golpes o sacudiéndola, como hacemos con un cojín o un edredón”.

Contexto: "Sacude un poco la almohada para mullirla" (CLAVE), "Mullela tierra de las viñas para que el agua penetre con más facilidad" (CLAVE).

pamela stf Clasificación: ecn $\quad$ Equivalente: sombrero (DIME)
DRAE: S
CLAVE: S
DEA: S

Acepción: "Sombrero de ala muy ancha que usan las mujeres".

Contexto: "A la fiesta al aire libre llevé una pamela a juego con el vestido" (CLAVE).

\footnotetext{
* Información obtenida en la empresa "Office Depot" de la ciudad de México.
} 


$\begin{array}{llll}\begin{array}{l}\text { pancho: } \\ \text { tan pancho }\end{array} & \text { ac. } 1 \text { loc.adv. } & \text { Clasificación: ecn } & \begin{array}{c}\text { Equivalente: } \\ \text { campante (DIME) }\end{array} \\ & & & \end{array}$

Acepción: "Se dice de la persona tranquila y que no se altera por cosas que alteran a los demás... Es una expresión informal".

Contexto: “CCómo podeís estar tan panchos cuando hay tanto trabajo?” (ANAYA).
pancho:
ac. 2 loc. adv.
Clasificación: ecn
Equivalente:
tan pancho

DRAE: S su pancho, ac. 2 CLAVE: S su pancho, ac. 2 DEA: S

Acepción: "Se dice de la persona que se queda tranquila y satisfecha después de hacer o decir algo que altera a otros... Es una expresión informal".

Contexto: "Cuando le ha dicho todo lo que pensaba de él se ha quedado tan pancha" (ANAYA), "No le afectaron mis críticas, porque se quedó tan pancha" (CLAVE).

parador st m Clasificación: ecn

Equivalente: hotel (DIME)

DRAE: S ac. 5

CLAVE: $\mathrm{S}$ forma, $\mathrm{N}$ ac

DEA: $\mathrm{S}$ ac. 1

Acepción: "Hotel que presta un servicio de gran calidad y cuyas instalaciones mantienen el estilo y tradiciones típicas del lugar en el que se encuentra".

Contexto: "Los paradores suelen estar instalados en antiguos edificios rehabilitados" (CLAVE).

parchís st m Clasificación: ecn Equivalente: parkesi (NID pcn; DEMD) DRAE: S

$$
\text { CLAVE: } \mathrm{S} \text { DEA: } \mathrm{S}
$$

Acepción: "Juego de mesa que consiste en hacer avanzar cinco fichas de color amarillo, rojo, azul o verde por un tablero dividido en casillas, según el número que indica un dado que se tira".

Contexto: "En el parchis, cuando comes una pieza de otro jugador, avanzas veinte casillas" (CLAVE).

parida stf Clasificación: ecn $\quad$ Equivalente: babosada (DIMEuso coloquial) DRAE: S ac. 2 CLAVE: S DEA: $\mathrm{S}$

Acepción: "Cosa extremadamente absurda o estúpida que hace o dice una persona... Es una palabra informal".

Contexto: "Esperabamos oír una historia interesante y sólo dijo cuatro paridas" (CLAVE).

piño st m Clasificación: ecn Equivalente: diente (DIME)
DRAE: $\mathrm{S}>$ diente
CLAVE: S
DEA: $\mathrm{S}$

Acepción: "Diente de las personas o los animales Es una palabra informal".

Contexto: "Se cayó de bruces y se rompió los piños" (CLAVE).

piragüismo st m Clasificación: ecn Equivalente: canotaje (DIME)
DRAE: S
CLAVE: S
DEA: $\mathrm{S}$

Acepción: "Deporte que consiste en navegar por un río, por un canal o por el mar en una piragua".

Contexto: "El piragüismo es un deporte olímpico" (CLAVE). 
plató st m Clasificación: ecn $\quad \begin{aligned} & \text { Equivalente: set (NID pcn; DEUM) } \\ & \text { DRAF:S }\end{aligned}$

Acepción: "Recinto cubierto de un estudio de cine o de televisión que se usa como escenario para rodar películas o realizar programas".

Contexto: "Los actores, ya vestidos y maquillados, esperaban al director en el plató" (CLAVE).

playeras $\quad$ st f pl Clasificación: ecn Equivalente: sandalias (DIME)

DRAE: S sv playero, ac. 5 CLAVE: S sv playero, ac. 2 DEA: $\mathrm{S}$ ac. 4

Acepción: "Calzado de verano, de tela fuerte y suela de goma".

Contexto: "Si vamos a cenar, me cambiaré de ropa y me quitaré las playeras y los pantalones cortos" (CLAVE).

recambio st m Clasificación: ecn Equivalente: refacción (DIME)
DRAE: S ac. 2
CLAVE: S ac. 2
DEA: $\mathrm{S}$ ac. 2

Acepción: "Pieza igual que otra que se utiliza para sustituirla cuando se rompe o estropea".

Contexto: "Compré en la papelería un recambio de cada color para mi bolígrafo" (CLAVE).

señorito, a ac. 1 st Clasificación: ecn Equivalente: joven (RA, LFG)
DRAE: S ac. 2
CLAVE: S ac. 2
DEA: $\mathrm{S}$ ac. 1

Acepción: "Manera de llamar las personas que trabajan en el servicio de una casa a los hijos de los dueños".

Contexto: "Estoy preparando la cena para el señorito" (CLAVE).

señorito ac. 2 st Clasificación: ecn Equivalente: junior/yúnior/ (DEUM)
DRAE: S ac. 3
CLAVE: S ac. 3
$D E A: \mathrm{S}$ ac. 6

Acepción: "Persona joven que no está acostumbrada a trabajar; también es la persona que actúa con demasiada delicadeza, como si fuera muy rica".

Contexto: "¡Mira qué señorito!, resulta que no quiere que sus amigos lo vean trabajar" (ANAYA), "Él no puede trabajar en cualquier cosa porque es un $s e-$ norito" (CLAVE).

slip st m Clasificación: ecn $\quad$ Equivalente: trusa (DIME)
DRAE: S
CLAVE: S
$D E A: \mathrm{S}$ ac. 1

Acepción: "Calzoncillo ajustado que no cubre las piernas".

Contexto: "Viste de forma deportiva y prefiere el slip" (CLAVE).

sofrito st m Clasificación: ecn Equivalente: condimento frito (DIME)
DRAE: S
CLAVE: $\mathrm{S}$ ac. 2
$D E A: \mathrm{S}$ ac. 2

Acepción: "Hortalizas cortadas en trozos pequeños y fritas en aceite a fuego lento".

Contexto: "Haz un sofrito de tomate para acompañar la carne" (CLAVE). 

soja stf Clasificación: emf DRAE: S
Equivalente: soya (DIME)
CLAVE: S
DEA: S

Acepción: "Planta que produce un fruto parecido a la judía con unas semillas de las que se saca aceite".

Contexto: "La soja es una legumbre muy nutritiva" (CLAVE).

$\begin{array}{lll}\text { somier } & \text { st m Clasificación: ecn } & \text { Equivalente: tambor (DIME, ac. 3) } \\ & \text { DRAE: } \mathrm{S} & \text { CLAVE: } \mathrm{S}\end{array}$

Acepción: "Base plana de madera o metal que tiene patas y sobre la que se pone el colchón para dormir a cierta distancia del suelo".

Contexto: "El somier de mi cama es de láminas de madera" (CLAVE).

suspense $\quad$ st m Clasificación: emf Equivalente: suspenso (DIME, ac. 1)

DRAE: S CLAVE: S DEA: S

Acepción: "Misterio o emoción que provoca una situación cuyo desenlace es incierto e imprevisible".

Contexto: "La película tiene mucho suspensey no se descubre quién es el asesino hasta el final".

\section{ANEXO 2}

\section{MEXICANISMOS}

abocarse vb pn Clasificación: mon Equivalente: dedicarse (ANAYA)
DRAE: S ac. 8
CLAVE: S mrd
$D E A$ : $\mathrm{S}$ forma, $\mathrm{N}$ ac.

Acepción: "Interesarse, dedicarse a resolver algo".

Contexto: "Nos abocamos al asunto de la reconstrucción del parque".
abonero st Clasificación: mdn Equivalente:

DRAE: $\mathrm{S} \mathrm{mx} \quad$ CLAVE: $\mathrm{N}$

DEA: N

Acepción: "Vendedor que cobra en abonos".

Contexto: "Mañana viene el abonero y tengo que pagarle el abono de este mes".
adolorido aj Clasificación: $\mathrm{mmf} \quad$ Equivalente: dolorido (ANAYA) DRAE: $\mathrm{S}>$ dolorido CLAVE: $\mathrm{S}$ mrd $\quad$ DEA: $\mathrm{S}>$ dolorido

Acepción: "Que siente o tiene dolor".

Contexto: "Quedé un poco adolorido de tanto ejercicio".

agarradera stf Clasificación: mon Equivalente: asa (ANAYA)

$$
\text { DRAE: } \mathrm{S}>\text { agarradero CLAVE: } \mathrm{N} \text { DEA: } \mathrm{S} \text { ac. } 1
$$

Acepción: "Parte de un objeto que sirve para agarrarlo".

Contexto: "Toma la olla por la agarradera para que no se te caiga". 
agarre ac. 2 st m Clasificación: mcn Equivalente: pelea (ANAYA) DRAE: $\mathrm{S}$ forma, $\mathrm{N}$ ac. CLAVE: $\mathrm{S}$ forma, $\mathrm{N}$ ac. DEA: $\mathrm{S}$ forma, $\mathrm{N}$ ac.

Acepción: "Pelea" (uso coloquial).

Contexto: "Si no los separan se hubieran dado un agarre delante de todos".

agarrón st m Clasificación: mcn

Equivalente: pelea (ANAYA), agarrada (DRAE, coloquial)

DRAE: $\mathrm{S} \mathrm{mx}$

CLAVE: $\mathrm{S}$ forma, $\mathrm{N}$ ac. $D E A$ : $\mathrm{S}$ forma, $\mathrm{N}$ ac.

Acepción: "Pelea" (uso coloquial).

Contexto: "Se dieron un buen agarrón".

agave st m Clasificación: mcn

DRAE: $\mathrm{S}>$ pita

Equivalente: pita (DRAE)

CLAVE: N

DEA: $\mathrm{S}>$ pita

Acepción: "Especie de maguey".

Contexto: "El agave azul sirve para producir tequila".

alebrije st m Clasificación: $m d n$

DRAE: $\mathrm{S} \mathrm{mx}$

Equivalente:-

CLAVE: N

DEA: N

Acepción: "Animal fantástico que se hace generalmente de cartón al que se le da forma y después se pinta de diversos colores".

Contexto: "Los que hacen alebrijes tienen una gran imaginación".

alzado ac. 1 aj Clasificación: mcn Equivalente: soberbio (ANAYA),

\section{engreído $(D R A E)$}

DRAE: S am

CLAVE: N DEA: S forma, $\mathrm{N}$ ac.

Acepción: "Que se cree más que los demás" (uso coloquial).

Contexto: "No me gusta hablar con ella porque es muy alzada".

alzado ac. 2 st Clasificación: mcn Equivalente: rebelde (ANAYA)
DRAE: S am
CLAVE: N
DEA: $\mathrm{S}$ forma, $\mathrm{N}$ ac.

Acepción: "Que combate al gobierno con armas" (uso coloquial).

Contexto: "Dicen que hay un grupo de alzados escondidos en la sierra".

amacizar vb Clasificación: mcn Equivalente: asegurar (DRAE)
DRAE: $\mathrm{S} \mathrm{mx}$
CLAVE: N
$D E A: \mathrm{N}$

Acepción: "Hacer que algo quede fuerte y seguro".

Contexto: "Amaciza bien la escalera contra la pared para que no se mueva".

andadera st $\mathrm{f}$ Clasificación: mcn Equivalente: andador (DRAE, ac. 5)

DRAE: S sv andadorac. 5 CLAVE: S sv andaderoac. 2 DEA: $\mathrm{S}$ forma, $\mathrm{N}$ ac.

Acepción: "Aparato con ruedas donde se mete a los niños para que aprendan a caminar".

Contexto: “'Mira!, ¡Ahí viene el niño en la andadera!”.

apachurrar vb Clasificación: mmf Equivalente: espachurrar (ANAYA)

DRAE: $\mathrm{S}>$ despachurrar CLAVE: $\mathrm{S}>$ espachurrar DEA: $\mathrm{S}>$ despachurrar

Acepción: "Apretar o empujar algo con mucha fuerza".

Contexto: "Quita el pan de allí para que no se apachurre". 
apagador st m Clasificación: mcn Equivalente: interruptor (ANAYA)
DRAE: S ac. $5 \mathrm{mx}$
CLAVE: N
DEA: $\mathrm{S}$ forma, $\mathrm{N}$ ac.

Acepción: "Botón o palanca que sirve para encender o apagar un aparato eléctrico".

Contexto: “¿Dónde está el apagador?”. $\begin{array}{cll}\text { apantallar vb } & \text { Clasificación: mcn } & \text { Equivalente: fardar (ANAYA, uso informal) } \\ \text { DRAE: } \mathrm{S} \text { ac. } 2 \mathrm{mx} & \text { CLAVE: } \mathrm{N} & \text { DEA: } \mathrm{S}\end{array}$

Acepción: "Sorprender a alguien, a veces con algo que no vale la pena" (uso coloquial).

Contexto: "Pedro te quiere apantallar".

aventado aj Clasificación: mcn Equivalente: lanzado (ANAYA) DRAE: $\mathrm{S}$ ac. $2 \mathrm{mx}$ CLAVE: $\mathrm{N}$ DEA: $\mathrm{S}$ forma, $\mathrm{Nac}$.

Acepción: "Atrevido, que hace lo que otros no se animan a hacer" (uso coloquial).

Contexto: "Aquí entre amigos, Ernesto es rete aventado".

aventar ac. 1 vb Clasificación: mcn Equivalente: arrojar (ANAYA)

DRAE: $\mathrm{S}$ forma, $\mathrm{N}$ ac. CLAVE: $\mathrm{S}$ ac. 2 mrd $\quad$ DEA: $\mathrm{S}$ forma, $\mathrm{N}$ ac.

Acepción: "Lanzar alguna cosa".

Contexto: “¡No avientes la ropa!, ¡Cuélgala!”.

aventar ac. 2 vb Clasificación: mcn Equivalente: empujar violentamente (CLAVE) DRAE: S ac. $10 \mathrm{mx}$ CLAVE: $\mathrm{Sac} .3 \mathrm{mrd}$ DEA: $\mathrm{S}$ forma, $\mathrm{N}$ ac.

Acepción: "Empujar con fuerza a alguien".

Contexto: "Había tanta gente en el metro que nomás nos aventábamos".

aventón ac. 1 st m Clasificación: mcn Equivalente: empujón (ANAYA)

DRAE: S ac. $2 \mathrm{mx} \quad$ CLAVE: $\mathrm{S}$ forma, N ac. DEA: $\mathrm{N}$

Acepción: "Empujón".

Contexto: "Dale un aventoncito al escritorio, muévelo un poco para que haya más espacio para la silla".

aventón ac. 2 st $\mathrm{m}$ Clasificación: mcn Equivalente: autostop (ANAYA)
DRAE: $\mathrm{S}$ ac. $1 \mathrm{mx}$
CLAVE: $\mathrm{S}$ mrd
DEA: $\mathrm{N}$

Acepción: "Lo que pides que te den en una carretera o en una calle para que te lleve gratis un vehículo" (uso coloquial).

Contexto: "Nos fuimos a Acapulco de aventón".

balero st m Clasificación: mcn Equivalente: boliche (DRAE)

DRAE: S su boliche ac. $1 \mathrm{mx}$ CLAVE: N DEA: N

Acepción: "Juguete de madera que tiene un palo terminado en forma de punta y un cilindro con un hoyo; ambas partes están unidas por un cordel; se coge por el palo y se lanza el cilindro, de manera que la punta del palo se ensarte en el hoyo".

Contexto: "Julio es muy bueno para el balero". 


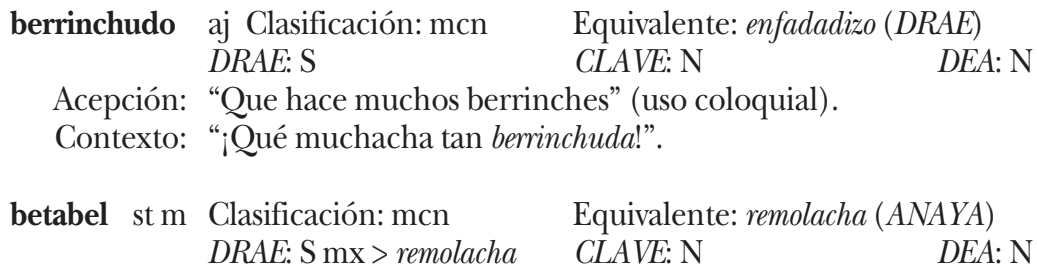

Acepción: "Planta que puede medir más de un metro de altura; su raíz, grande y carnosa de color rojo oscuro, se come y también se aprovecha para sacar de ella azúcar".

Contexto: "Voy a preparar una ensalada de betabel".

blanquillo st m Clasificación: mcn Equivalente: huevo (ANAYA) DRAE: $\mathrm{S}$ ac. $7 \mathrm{mx} \quad$ CLAVE: $\mathrm{S}$ forma, $\mathrm{Nac}$. DEA: $\mathrm{S}$ forma, $\mathrm{N}$ ac.

Acepción: "Huevo, sobre todo de gallina" (uso popular).

Contexto: "Hoy desayuné blanquillos".

$\begin{array}{ll}\text { canotaje st m Clasificación: mcn } & \text { Equivalente: piragüismo (ANAYA) } \\ & \text { DRAF: } \mathrm{N}\end{array}$

Acepción: "Deporte en el que compiten varias canoas".

Contexto: "En el canotaje tienes que remar lo más rápido que puedas para llegar a la meta antes que los demás".

cantador aj Clasificación: mcn Equivalente: cantor (ANAYA)

DRAE: $\mathrm{S}$ CLAVE: $\mathrm{N}$ DEA: $\mathrm{S}>$ cantor

Acepción: "Que canta".

Contexto: "iHoy despertaste muy cantadora!".

cantaleta stf Clasificación: mcn

Equivalente: cantilena (ANAYA)

DRAE: $\mathrm{S}$ am > estribillo CLAVE: $\mathrm{S}$ mrd

$D E A: \mathrm{N}$

Acepción: "Algo que cansa y que se dice a cada rato".

Contexto: "¡No sigas con tu misma cantaleta! ¡Ya te dije que no puedo ir contigo al cine!".

catarina stf Clasificación: mcn Equivalente: mariquita (ANAYA)
DRAE: N
CLAVE: S mrd
$D E A: \mathrm{N}$

Acepción: "Catarinita" (se usa en algunos lugares).

Contexto: > catarinita

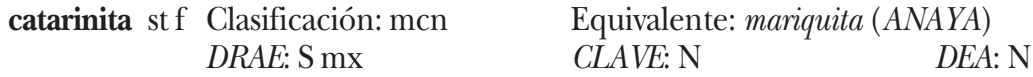

Acepción: "Insecto de color rojo, amarillo o anaranjado, con puntitos negros; se alimenta de hojas".

Contexto: "Dicen que las catarinitas traen buena suerte".

chorrillo st m Clasificación: mcn Equivalente: cagalera (DRAE, uso coloquial) DRAE: N CLAVE: $\mathrm{S}$ mrd DEA: $\mathrm{S}$ forma, $\mathrm{Nac}$.

Acepción: "Diarrea" (uso popular).

Contexto: "Le dio chorrillo porque comió carne descompuesta". 
chotear ac. 1 vb Clasificación:mcn Equivalente: pitorrearse (ANAYA, uso informal) DRAE: S CLAVE: S (pn) DEA: S (pn)

Acepción: "Hacer burla de alguien o de algo" (uso coloquial).

Contexto: "Las niñas chotearon a Juanito".

chotear ac. 2 vb Clasificación: mcn Equivalente: estropear (ANAYA)

DRAE: $\mathrm{S}$ ac. $4 \mathrm{mx} \quad$ CLAVE: $\mathrm{S}$ forma, $\mathrm{N}$ ac. DEA: $\mathrm{S}$ forma, $\mathrm{N}$ ac.

Acepción: "Perder una cosa la novedad" (uso coloquial).

Contexto: "Ya chotearon esa canción de tanto que se escucha por todas partes".

chueco ac. 1 aj, st Clasificación: mcn Equivalente: torcido (DRAE)

DRAE: S ac. $2 \mathrm{mx} \quad$ CLAVE: $\mathrm{S}$ ac. $1 \mathrm{mrd}$ DEA: $\mathrm{N}$

Acepción: "Que no está derecho, que tiene forma curva".

Contexto: "Este clavo está chueco".

chueco ac. 2 aj, st Clasificación: mon Equivalente: tramposo (ANAYA)

DRAE: $\mathrm{S}$ forma, $\mathrm{N}$ ac. $\quad$ CLAVE: $\mathrm{S}$ ac. 4 mrd DEA: $\mathrm{N}$

Acepción: "Tramposo, que no juega limpio" (uso coloquial).

Contexto: "No vuelvo a confiar en ti, eres muy chueco".

chueco ac. 3 aj, st Clasificación: mcn Equivalente: zocato (DRAE, coloquial)

DRAE: $\mathrm{S}$ forma, $\mathrm{N}$ ac. $\quad$ CLAVE: $\mathrm{S}$ ac. $3 \mathrm{mrd}$ DEA: $\mathrm{N}$

Acepción: "Zurdo" (uso coloquial).

Contexto: "Ese pícher [lanzador, en el juego de beisbol] es chueco".

chueco ac. 4 aj, st Clasificación: mon Equivalente: cojo (ANAYA)

DRAE: $\mathrm{S}$ forma, $\mathrm{N}$ ac. CLAVE: $\mathrm{S}$ forma, $\mathrm{N}$ ac. DEA: $\mathrm{N}$

Acepción: "Persona que tiene una pierna más corta que la otra" (uso coloquial).

Contexto: "Así nació, chueco, por eso usa bastón".

comal st m Clasificación: mdn Equivalente:-

DRAE: S mx CLAVE: S DEA: N

Acepción: "Plato grande, delgado y plano de barro o de metal donde se hacen o se calientan alimentos como las tortillas".

Contexto: "Pon el comal en la estufa para empezar a calentar las tortillas".

comelón aj Clasificación: mmf Equivalente: comilón (ANAYA)

DRAE: $\mathrm{S} \mathrm{mx}>$ comilón $\quad$ CLAVE: $\mathrm{S}$ mrd > comilón DEA: $\mathrm{N}$

Acepción: "Que come mucho" (uso coloquial).

Contexto: "Tengo un perro muy comelón".

computación st $\mathrm{f}$ Clasificación: mcn Equivalente: informática (ANAYA)

DRAE: $\mathrm{S}$ ac. 2 am>informática CLAVE: $\mathrm{S}$ forma,N DEA: $\mathrm{S}$ ac.2>informática

Acepción: "Parte de la ingeniería que tiene como propósito construir computadoras y desarrollar los programas de cómputo".

Contexto: "Mi hermano estudió computación". 
correlón aj Clasificación: mon Equivalente: corredor (ANAYA) DRAE: $\mathrm{S}$ ac. $1 \mathrm{am}$ CLAVE: N DEA $\mathrm{N}$

Acepción: "Que corre mucho" (uso coloquial).

Contexto: "Tu perrito es muy correlón".

corrido ac. 1 aj Clasificación: mon Equivalente: continuo (ANAYA) DRAE: $\mathrm{S}$ forma, $\mathrm{N}$ ac. CLAVE: $\mathrm{S}$ forma, $\mathrm{N}$ ac. DEA: $\mathrm{S}$ forma, $\mathrm{N}$ ac.

Acepción: "Que no se detiene o interrumpe".

Contexto: "Allí trabajan en horario corrido, de las 8 de la mañana a las 5 de la tarde".

corrido ac. 2 st $m$ Clasificación: mdn Equivalente: NIA pcn

DRAE: $\mathrm{S}$ ac. $9 \mathrm{mx} \quad$ CLAVE: $\mathrm{S}$ ac. $3 \mathrm{mx}$

DEA: S ac. $8 \mathrm{mx}$

Acepción: "Canción popular; sus versos tienen casi siempre ocho sílabas, y generalmente tratan sobre la vida de algún personaje o de un momento importante de la historia".

Contexto: "Tengo un disco de corridos de la revolución".

corrido $>$ corrida ac. 3 stf Clasificación: $\mathrm{mcn}$

Equivalente: vuelta $(A N A Y A)$

DRAE: $\mathrm{S}$ forma, $\mathrm{N}$ ac. $\quad$ CLAVE: $\mathrm{S}$ forma, $\mathrm{N}$ ac. DEA: $\mathrm{S}$ forma, $\mathrm{N}$ ac.

Acepción: "Hecho de hacer correr algo o de pasarlo de un lado a otro".

Contexto: "El autobús hizo cuatro corridas en la mañana y todavía hay muchos pasajeros".

corrido > corrida ac. 4 st $\mathrm{f}$ Clasificación: mcn Equivalente: carrera (ANAYA)

DRAE: $\mathrm{S}$ forma, $\mathrm{N}$ ac. $\quad$ CLAVE: $\mathrm{S}$ forma, $\mathrm{N}$ ac. DEA: $\mathrm{S}$ forma, $\mathrm{N}$ ac.

Acepción: "Carrera que hace alguien llevando algo".

Contexto: "Dio una buena corrida con el paquete y lo entregó a tiempo".

curita st f Clasificación: mcn Equivalente: tirita (ANAYA)

DRAE: $\mathrm{S}>$ tirita CLAVE: $\mathrm{S}$ mrd DEA: $\mathrm{N}$

Acepción: "Tira de tela que se pega sobre una herida pequeña para curarla y protegerla mientras sana”.

Contexto: "Toma, ponte esta curita en el brazo".

delegación ac. 2 st $\mathrm{f}$ Clasificación: mcn Equivalente: distrito (ANAYA)

DRAE: $\mathrm{S}$ ac. $5 \mathrm{mx} \quad$ CLAVE: $\mathrm{S}$ forma, $\mathrm{N}$ ac. DEA: $\mathrm{S}$ forma, $\mathrm{N}$ ac.

Acepción: "Cada una de las zonas en las que se divide el Distrito Federal".

Contexto: "Coyoacán es una delegación que está dentro de la ciudad de México".

delegación ac. 3 st $\mathrm{f}$ Clasificación: mon Equivalente: edificio de la junta de distrito DRAE: $\mathrm{S}$ ac. $6 \mathrm{mx} \quad$ CLAVE: $\mathrm{S}$ forma, $\mathrm{N}$ ac. DEA: $\mathrm{S}$ forma, $\mathrm{N}$ ac.

Acepción: "Edificio donde trabajan los empleados de cada una de esas zonas [delegaciones]".

Contexto: "Pintaron las paredes de la delegación". 

deslave st $\mathrm{m}$ Clasificación: $\mathrm{mcn} \quad$ Equivalente: derrubio $(D R A E)$ DRAE: $\mathrm{S}$ am > derrubio CLAVE: $\mathrm{N}$ DEA: $\mathrm{N}$

Acepción: "Separación de tierra y piedras de una montaña o un cerro por causa de las lluvias, la humedad o un temblor, etc.".

Contexto: "Si quieren que no haya deslaves no corten los árboles".

desmañanarse vb pn Clasificación: mdn Equivalente: madrugar (ANAYA)

$$
\text { DRAE: } \mathrm{S} \mathrm{mx}>\text { madrugar CLAVE: } \mathrm{S} \text { mrd DEA: } \mathrm{N}
$$

Acepción: "Levantarse muy temprano".

Contexto: "Se desmañanó para llegar a tiempo".

disparejo aj Clasificación: mcn Equivalente: desparejo (CLAVE), dispar (CLAVE, DRAE)

DRAE: $\mathrm{S}>$ dispar CLAVE: $\mathrm{S}$

DEA: $\mathrm{S}>$ desigual

Acepción: "Que no es igual a otro, que no está parejo".

Contexto: "Las patas de la mesa están un poco disparejas".

estampilla st $\mathrm{f}$ Clasificación: $\mathrm{mcn}$

Equivalente: sello (ANAYA)

DRAE: S ac. 2 am

CLAVE: S ac. 2 mrd DEA: $\mathrm{S}$ forma, $\mathrm{N}$ ac.

Acepción: "Timbre de correos".

Contexto: "Mi primo colecciona estampillas de muchos países".

foro ac. 3 st m Clasificación: mcn Equivalente: estudio (ANAYA)

DRAE: $\mathrm{S}$ forma, $\mathrm{N}$ ac. CLAVE: $\mathrm{S}$ forma, $\mathrm{N}$ ac. DEA: $\mathrm{S}$ forma, $\mathrm{N}$ ac.

Acepción: "Edificio donde se construyen escenarios para filmar películas o programas de televisión".

Contexto: "Los actores deberán presentarse al foro ocho para iniciar la filmación".

gringo st, aj Clasificación: mcn Equivalente: estadounidense (ANAYA)

DRAE: $\mathrm{S}$ ac. 3 am CLAVE: $\mathrm{S}$ DEA: $\mathrm{S}$ ac. 1

Acepción: "De los Estados Unidos de América; extranjero, sobre todo cuando es rubio" (uso coloquial).

Contexto: "Mi prima tiene un novio gringo".

gripa st $\mathrm{f}$ Clasificación: $\mathrm{mcn} \quad$ Equivalente: gripe (ANAYA)
DRAE: $\mathrm{S} \mathrm{mx}>$ gripe
CLAVE: S mrd
DEA: $\mathrm{N}$

Acepción: "Gripe" [Catarro, enfermedad que te dé tos, fiebre y dolor de cabeza] (uso coloquial).

Contexto: "Si usted quiere le puedo vender estas pastillas para la gripe".

guacamaya st $\mathrm{f}$ Clasificación: mmf Equivalente: guacamayo (ANAYA) DRAE: S ac. $2 \mathrm{mx} \quad$ CLAVE: S [ guacamaya-o] DEA: N

Acepción: "Ave parecida al papagayo, con las plumas de muchos colores brillantes y cola larga".

Contexto: "En el circo vi un espectáculo con guacamayas amaestradas". 
guacamole st m Clasificación: mdn Equivalente:-

DRAE: $\mathrm{S}$ ac. $1 \mathrm{mx} \quad$ CLAVE: $\mathrm{S}$ DEA: $\mathrm{S}$ (típico de México)

Acepción: "Ensalada o salsa con aguacate molido o picado, al que se le agrega jitomate, cebolla y chile verde; después se le pone sal y, a veces, un poco de limón".

Contexto: "El guacamole te quedó muy sabroso".

guaje ac. 1 st m Clasificación: mdn Equivalente:DRAE: $\mathrm{S}$ ac. $2 \mathrm{mx}$ CLAVE: N DEA: $\mathrm{S}$ forma, $\mathrm{N}$ ac.

Acepción: "Planta que da unos frutos de cáscara dura, en forma de globo".

Contexto: "En la carretera vimos varios guajes".

guaje ac. 2 st m Clasificación: mdn Equivalente:DRAE: $\mathrm{S}$ ac. $3 \mathrm{mx} \quad$ CLAVE: $\mathrm{N}$ DEA: $\mathrm{S}$ forma, $\mathrm{N}$ ac.

Acepción: "Fruto de esa planta".

Contexto: "Todavía no es tiempo de cortar los guajes".

guaje ac. 3 st m Clasificación: mdn Equivalente:DRAE: $\mathrm{S}$ forma, $\mathrm{N}$ ac. CLAVE: $\mathrm{N}$ DEA: $\mathrm{S}$ forma, $\mathrm{N}$ ac.

Acepción: "Recipiente que se hace con la cáscara seca de ese fruto".

Contexto: "Guardé agua en el guaje”.

guajolote st m Clasificación: mcn Equivalente: pavo (ANAYA)
DRAE: S ac. $1 \mathrm{mx}$
CLAVE: S mrd
DEA: N

Acepción: "Ave de corral que no tiene plumas en la cabeza ni en el cuello; debajo del pico le cuelga una tira roja y carnosa".

Contexto: "En el rancho tengo muchos guajolotes".

guarache st m Clasificación: mcn Equivalente: sandalia (ANAYA)
DRAE: $\mathrm{S} \mathrm{mx}$
CLAVE: S
$D E A: \mathrm{N}$

Acepción: > huarache [Calzado formado por una suela de la que salen tiras de cuero entretejidas].

Contexto: "Estos huaraches son muy cómodos para caminar".

guarura st m Clasificación: mon Equivalente: guardaespaldas (ANAYA)
DRAE: $\mathrm{N}$
CLAVE: N
$D E A: \mathrm{N}$

Acepción: "Hombre fuerte que se encarga de proteger a una persona importante, como un político o un empresario" (uso coloquial).

Contexto: "El guarura disparó contra los asaltantes".

$\begin{array}{lll}\text { güero st, aj Clasificación: mcn } & \text { Equivalente: rubio (ANAYA) } \\ & \text { DRAE: } \mathrm{S} \mathrm{mx} & \text { CLAVE: } \mathrm{NEA: \textrm {N }}\end{array}$

Acepción: "Persona de piel blanca que puede tener el cabello claro" (uso coloquial).

Contexto: "Aquella güera es mi amiga". 
maguey st m Clasificación: mon Equivalente: pita (DRAE)

DRAE: $\mathrm{S}$ am > pita CLAVE: $\mathrm{S}$ mrd DEA: $\mathrm{S}>$ pita

Acepción: "Planta con hojas muy grandes, gruesas y carnosas que terminan en una punta muy dura; el tallo es corto y las hojas se abren casi desde el suelo; se usa para hacer bebidas como el pulque y el tequila; también da una fibra que sirve para hacer tejidos".

Contexto: "Ese tapete es de fibra de maguey".
maquila st $\mathrm{f}$ Clasificación: $\mathrm{mcn}$
Equivalente: manufactura (ANAYA)
DRAE: $\mathrm{S}$ forma, $\mathrm{N}$ ac.
CLAVE: $\mathrm{N}$
$D E A$ : $\mathrm{S}$ forma, $\mathrm{N}$ ac.

Acepción: "Lo que se hace en las fábricas que se dedican a maquilar".

Contexto: "El camión lleva la maquila de las piezas de televisión".

$\begin{array}{ccc}\text { maquilar vb Clasificación: mcn } & \text { Equivalente: manufacturar (DRAE) } \\ \text { DRAE: } \mathrm{S} \mathrm{mx} & \text { CLAVE: } \mathrm{N}\end{array}$

Acepción: "Hacer algunas de las partes de algún producto en una fábrica para que sea armado en otra fábrica".

Contexto: "En esa fábrica maquilan partes de aviones".

maquillista st Clasificación: mcn Equivalente: maquillador (ANAYA)

DRAE: N CLAVE: N DEA: $\mathrm{N}$

Acepción: "Persona que trabaja maquillando a otras".

Contexto: "La maquillista está arreglando a la actriz principal".

mollete st m Clasificación: mdn Equivalente:

DRAE: $\mathrm{S}$ forma, $\mathrm{N}$ ac. $\quad$ CLAVE: $\mathrm{S}$ forma, $\mathrm{N}$ ac. DEA: $\mathrm{S}$ forma, $\mathrm{N}$ ac.

Acepción: "Bolillo tostado que se unta con mantequilla o con frijoles refritos y queso".

Contexto: "iVamos a hacer unos molletes!".

mosco st m Clasificación: mon Equivalente: mosquito (ANAYA)

DRAE: $\mathrm{S}$ ac. $2>$ mosquito CLAVE: $\mathrm{S}$ mrd DEA: $\mathrm{S}$ forma, $\mathrm{N}$ ac.

Acepción: "Insecto pequeño que tiene un aguijón para picar y chupar sangre; cuando vuela hace un zumbido muy fuerte con sus alas".

Contexto: "Dejé la ventana abierta y entraron y me picaron los moscos".

ocote ac. 1 st m Clasificación: mdn Equivalente:-
DRAE: $\mathrm{S} \mathrm{mx}$
CLAVE: N
DEA: N

Acepción: "Árbol parecido al pino".

Contexto: "El ocote puede crecer más de 20 metros".

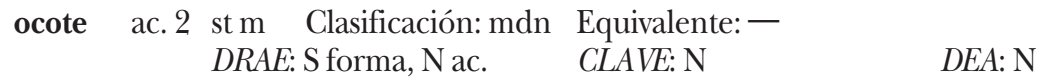

Acepción: "Madera de este árbol [ocote]".

Contexto: "El ocotese enciende con mucha facilidad". 
octágono st m Clasificación: mmf Equivalente: octógono (ANAYA)
DRAE: $\mathrm{S}>$ octógono
CLAVE: $\mathrm{S}>$ octógono
DEA: $\mathrm{S}>$ octógono

Acepción: "Figura geométrica que tiene ocho lados iguales".

Contexto: "Este espejo tiene la forma de un octágono".

olán

st m Clasificación: mcn

Equivalente: volante (ANAYA)

DRAE: N

CLAVE: $\mathrm{N}$

DEA: $\mathrm{N}$

Acepción: "Adorno de tela en forma de ondas que llevan algunos vestidos y blusas".

Contexto: "Mi vestido tiene varios olanes en las mangas".

olote st m Clasificación: mcn

Equivalente: zuro (DRAE)

DRAE: $\mathrm{S} \mathrm{mx}>$ zuro

CLAVE: $\mathrm{N}$

DEA: N

Acepción: "Parte dura de la mazorca del maíz, la que queda cuando se le quitan los granos".

Contexto: "Juntaron los olotes en un canasto".

parvada st $\mathrm{f}$ Clasificación: mcn Equivalente: bandada (ANAYA)

DRAE: $\mathrm{S}$ ac. $3 \mathrm{mx}>$ bandada CLAVE: $\mathrm{N}$

$D E A$ : $\mathrm{S}$ forma, $\mathrm{N}$ ac.

Acepción: "Conjunto de aves que vuelan juntas".

Contexto: "¡Mira!, jahí va una parvada de patos!”.

pasante st mf Clasificación: mon Equivalente: estudiante

universitario no titulado

DRAE: $\mathrm{S}$ ac. $7 \mathrm{mx} \quad$ CLAVE: $\mathrm{S}$ forma, $\mathrm{N}$ ac. DEA: $\mathrm{S}$ forma, $\mathrm{N}$ ac.

Acepción: "Persona que ha terminado los cursos de la universidad, pero no se ha titulado".

Contexto: "Mi hermana es pasante de ingeniería".

refacción stf Clasificación: mcn Equivalente: recambio (ANAYA)

DRAE: $\mathrm{S}$ ac. $7 \mathrm{mx} \quad$ CLAVE: $\mathrm{S}$ forma, $\mathrm{N}$ ac. DEA: $\mathrm{S}$ forma, $\mathrm{N}$ ac.

Acepción: "Pieza nueva de una maquinaria que se pone cuando la vieja ya no sirve".

Contexto: "Ya trajeron las refacciones para el motor".

refaccionaria stf Clasificación: $\mathrm{mcn}$ Equivalente: tienda de recambios DRAE: $\mathrm{S}$ ac. $2>$ madrugador CLAVE: $\mathrm{N}$ DEA: $\mathrm{S}$ forma, $\mathrm{N}$ ac.

Acepción: "Establecimiento donde venden refacciones, sobre todo para automóviles o camiones".

Contexto: "Aquí cerca hay una refaccionaria".

tempranero aj Clasificación: mcn Equivalente: madrugador (ANAYA)

DRAE: S ac. $2>$ madrugador CLAVE: ac. 3 DEA: ANAYA > temprano

Acepción: "Que ocurre muy temprano o antes del momento esperado".

Contexto: "Al minuto de juego metí un gol tempranero".

tezontle stm Clasificación: mdn Equivalente:-
DRAE: $\mathrm{S} \mathrm{mx}$
CLAVE: N
$D E A: \mathrm{N}$

Acepción: "Piedra volcánica, muy porosa, de color rojo oscuro".

Contexto: "Hizo un muro de tezontle". 
tianguis st m Clasificación: mcn Equivalente: mercadillo (ANAYA)
DRAE: $\mathrm{S} \mathrm{mx}$
CLAVE: S mrd
$D E A: \mathrm{N}$

Acepción: "Mercado al aire libre que se pone en alguna calle, generalmente un día a la semana".

Contexto: "Me gusta ir a comprar al tianguis".

\section{ANEXO 3}

\section{NO ESPAÑOLISMOS DE ANAYA (CRITERIO DE NOMENCLATURA)}

anatómico, aj
andaluz, aj, $\mathrm{st}$
aposición, $\mathrm{st} \mathrm{f}$
aragonés, aj, $\mathrm{st}$
atril, $\mathrm{st} \mathrm{m}$,
atrofiado, aj
blancuzco, aj
bronquio, $\mathrm{st} \mathrm{m}$
bronquitis, $\mathrm{st} \mathrm{f}$
bus, $\mathrm{st} \mathrm{m}$
buscador, $\mathrm{st}$
butano, $\mathrm{st} \mathrm{m}$
cacereño, aj, $\mathrm{st}$
cachalote, $\mathrm{st} \mathrm{m}$
cafeína, $\mathrm{st} \mathrm{f}$
cejijunto, aj
centauro, $\mathrm{st} \mathrm{m}$
centesimal, aj
compañerismo, $\mathrm{st} \mathrm{m}$
comparecer, vb
correaje, $\mathrm{st} \mathrm{m}$
corrector, aj, st
cubertería, $\mathrm{st} \mathrm{f}$
cucharilla, $\mathrm{st} \mathrm{f}$
discriminación, st $\mathrm{f}$
donostiarra, aj, $\mathrm{st} \mathrm{m} \mathrm{f}$
encabezamiento, st $\mathrm{m}$
escarola, $\mathrm{st} \mathrm{f}$
escenografia, st $\mathrm{f}$

anatómico, aj andaluz, aj, st aposición, $\mathrm{st} \mathrm{f}$ atril, st m atrofiado, aj blancuzco, aj bronquitis, st $\mathrm{f}$ bus, st m cacereño, aj, st cachalote, st m cafeina, st $\mathrm{f}$ cejijunto, aj centauro, st $\mathrm{m}$ contesimal, aj st $\mathrm{m}$ cuberteria, cucharilla, st $\mathrm{f}$ discriminación, $\mathrm{st} \mathrm{f}$ encabezamiento, $\mathrm{st} \mathrm{m}$ escenografía, st $\mathrm{f}$ exhibicionista, st $\mathrm{m} \mathrm{f}$ formatear, vb funcional, aj honda, st $\mathrm{f}$ inca, aj, st $\mathrm{m} \mathrm{f}$ incidencia, $\mathrm{st} \mathrm{f}$ interferencia, $\mathrm{st} \mathrm{f}$ interfono, st $\mathrm{m}$ internet, st inventiva, $\mathrm{st} \mathrm{f}$ inversión, st m itinerante, aj jeans, st m pl jeque, st $\mathrm{m}$ legislatura, $\mathrm{st} \mathrm{f}$

llana, st $\mathrm{f}$ llevadero, aj malagueño, aj, st mamitis, st $\mathrm{f}$ mimosa, st $\mathrm{f}$ minima, st $\mathrm{f}$ monosemia, st $\mathrm{f}$ monosémico, aj montacargas, st m multicolor, aj narrativa, st f ortodoncia, st $\mathrm{f}$ pamplonica, aj, st $\mathrm{m} \mathrm{f}$ pandereta, st $\mathrm{f}$ parabólica, aj, st f paralimpiada, $\mathrm{st} \mathrm{f}$ paralimpico, aj parapente, st $\mathrm{m}$ parapetado, aj pictograma, st m pipeta, st $\mathrm{f}$ pirado, aj, st platea, st $\mathrm{f}$ playback, st m playero, aj respectivamente, av respingón, aj salina, $\mathrm{st} \mathrm{f}$ slogan, st m software, st m solano, $\mathrm{st} \mathrm{m}$ subacuático, aj subdelegado, st subdesarrollado, aj subdirector, st sucesor, aj, st sudamericano, aj, st surf, st m tilo, st $\mathrm{m}$ tinaja, st $\mathrm{f}$ tinerfeño, aj, st videoteca, st $\mathrm{f}$ vitoriano, aj, st 


\section{ANEXO 4}

\section{NO MEXICANISMOS DE DIME (CRITERIO DE NOMENCLATURA)}

abismal, aj $\mathrm{m} \mathrm{f}$ abnegación, $\mathrm{st} \mathrm{f}$ abogacía, st $\mathrm{f}$ abombar, $\mathrm{vb}$ acaecer, vb acanalado, aj acaparador, st, aj acaparar, vb acaudalado, aj accidentarse, $\mathrm{vb} \mathrm{pn}$ acecho, st aceitar, $\mathrm{vb}$ adjuntar, vb adjunto, aj, st admisión, st $\mathrm{f}$ adobar, $\mathrm{vb}$ adobo, st $\mathrm{m}$ adopción, $\mathrm{st} \mathrm{f}$ agasajar, vb agasajo, st m agitación, $\mathrm{st} \mathrm{f}$ agitador, aj, st aglomerar, vb, vb pn aldaba, st $\mathrm{f}$ aledaño, aj alejamiento, st m ¡aleluya!, ij alentador, aj alentar, vb aleteo, $\mathrm{st} \mathrm{m}$ alevoso, aj alumnado, st $\mathrm{m}$ amado, aj, st amagar, vb amainar, aj amargado, aj anal, aj $\mathrm{m} \mathrm{f}$ analfabetismo, st $\mathrm{m}$ anarquista, aj andamiaje, $\mathrm{st} \mathrm{m}$ andanada, st $\mathrm{f}$ apacentar, $\mathrm{vb}$ apache, aj $\mathrm{m} \mathrm{f,} \mathrm{st} \mathrm{m} \mathrm{f}$ apaisado, aj

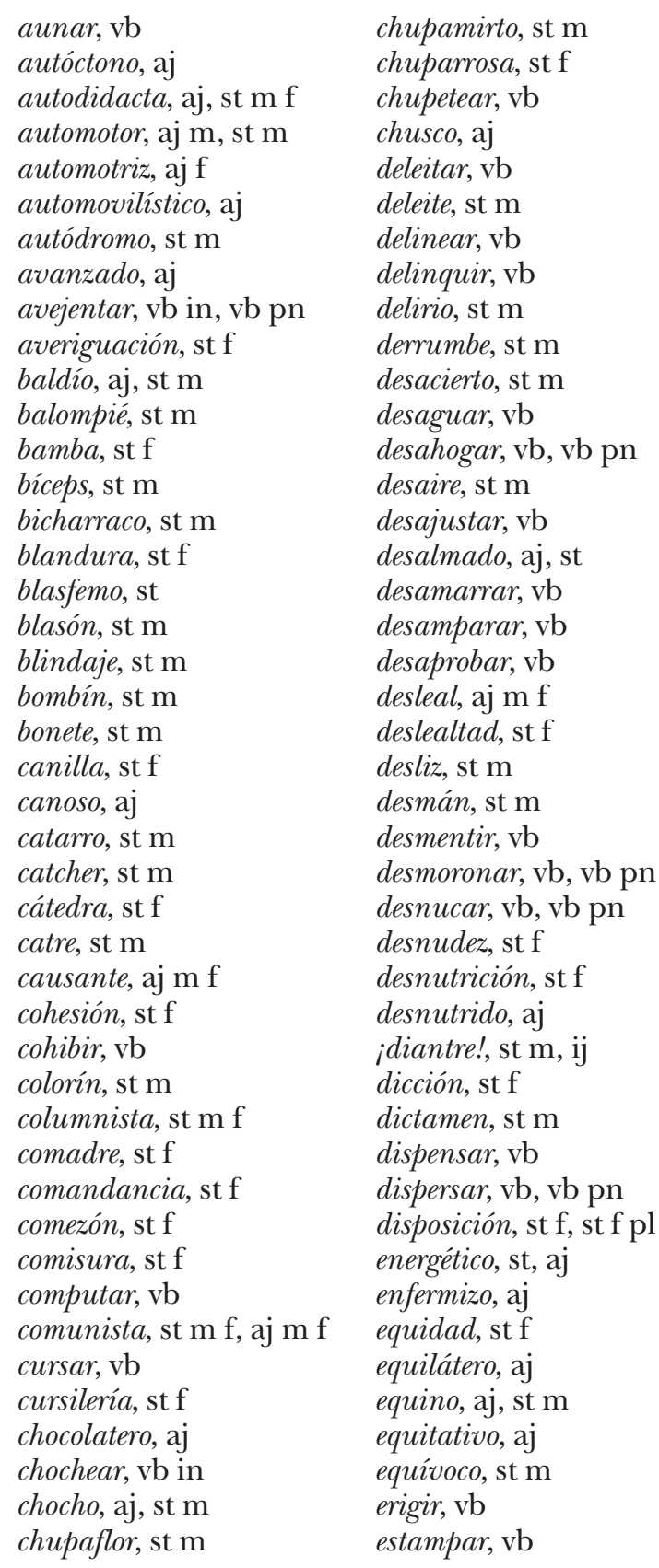


formulario, st m fornicar, vb in forraje, st m forrajero, aj graduación, st f grafema, st m grafito, st $\mathrm{m}$ graminea, st $\mathrm{f}$ gritón, aj iguau!, on guayabera, st $\mathrm{f}$ guayabo, st $\mathrm{m}$ gubernamental, aj $\mathrm{m} \mathrm{f}$ guerrerense, aj st $\mathrm{m} \mathrm{f}$ gula, st $\mathrm{f}$ honestidad, st $\mathrm{f}$ honorable, aj $\mathrm{m} \mathrm{f}$ inconcebible, aj $\mathrm{m} \mathrm{f}$ incondicional, aj $\mathrm{m} \mathrm{f}$ incorregible, aj $\mathrm{m} \mathrm{f}$ inconforme, aj $\mathrm{m} \mathrm{f}$ inculcar, vb magnetismo, st $\mathrm{m}$ magnolia, st $\mathrm{f}$ mapache, st $\mathrm{m}$ maraña, st $\mathrm{f}$

médula, $\mathrm{st} \mathrm{f}$
medular, aj $\mathrm{m} \mathrm{f}$
mejora, $\mathrm{st} \mathrm{f}$
mejoramiento, $\mathrm{st} \mathrm{m}$
molienda, $\mathrm{st} \mathrm{f}$
mortalidad, $\mathrm{st} \mathrm{f}$
mortandad, $\mathrm{st} \mathrm{f}$
mortificar, $\mathrm{vb}, \mathrm{vb} \mathrm{pn}$
municipal, aj $\mathrm{m} \mathrm{f}$
obtuso, aj
ocasional, aj $\mathrm{m} \mathrm{f}$
occidental, aj $\mathrm{m} \mathrm{f}$
ocelote, $\mathrm{st} \mathrm{m}$
oleaginoso, aj
oligarquí, $\mathrm{st} \mathrm{f}$
rededor, $\mathrm{st} \mathrm{m}$
rédito, $\mathrm{st} \mathrm{m}$
redoble, $\mathrm{st} \mathrm{m}$
redondeado, aj
redundar, $\mathrm{vb}$
reemplazar, $\mathrm{vb}$
refajo, $\mathrm{st} \mathrm{m}$
referendo, $\mathrm{st} \mathrm{m}$
relajación, $\mathrm{st} \mathrm{f}$
relajo, $\mathrm{st} \mathrm{m}$
releer, vb

relegar, vb retoñar, vb in retoño, $\mathrm{st} \mathrm{m}$ retorcido, aj retractarse, vb pn ruptura, st $\mathrm{f}$ rutinario, aj socialista, aj $\mathrm{m} \mathrm{f}, \mathrm{st} \mathrm{m} \mathrm{f}$ socializar, vb sociología, $\mathrm{st} \mathrm{f}$ soda, $\mathrm{st} \mathrm{f}$ soez, aj $\mathrm{m} \mathrm{f}$ sojuzgar, vb templanza, st $\mathrm{f}$ tico, aj veras, sin $\mathrm{CG}$ veraz, aj $\mathrm{m} \mathrm{f}$ verbigracia, sin CG verdecer, vb in verdolaga, $\mathrm{st} \mathrm{f}$ verdor, $\mathrm{st} \mathrm{m}$ verdulero, st vereda, st $\mathrm{f}$ veredicto, $\mathrm{st} \mathrm{m}$ verga, st $\mathrm{f}$ vergel, st $\mathrm{m}$

ANEXO 5

\section{VOCABLOS DE ANAYA ENCONTRADOS EN DIME}

abundancia
abundante
abundar
aburrido
aburrimiento
aburrir
abusar
abuso
abusón
acá
acabado
acabar
acacia
agitar
aglomeración

\author{
agobiar \\ agobio \\ agolparse \\ agonía \\ agonizar \\ agosto \\ agotamiento \\ agotar \\ agraciado \\ agradable \\ ambiental \\ ambientar \\ ambiente \\ ambigüedad \\ ambiguo
}

ámbito
ambos
ambulancia
ambulante
amén
amenaza
amenazar
americano
amígdala
amigo
amistad
amistoso
amnesia
amnistía
amo

amodorrarse

amoldar

amonestar

amoniaco

amoníaco

amontonar

anca

ancho

anchoa

anchura

anciano

ancla

anclar

andamio

andar 


\begin{tabular}{|c|c|c|c|}
\hline añoranza & arcángel & blando & cagada \\
\hline añorar & archipiélago & blanquear & cagado \\
\hline aorta & archivar & blanquecino & cagar \\
\hline apacible & atribuir & blasfemar & cagarruta \\
\hline apaciguar & atributo & blasfemia & cagón \\
\hline apadrinar & atrio & blindar & caída \\
\hline apagado & atrocidad & brindis & caído \\
\hline apagar & atropellar & brío & caimán \\
\hline apagón & atropello & brisa & caja \\
\hline apalabrar & atroz & británico & cajero \\
\hline apalear & atuendo & brizna & catalejo \\
\hline aparador & automático & broca & catálogo \\
\hline apego & automatizar & brocha & catar \\
\hline apelación & automóvil & brochazo & catarata \\
\hline apelar & automovilismo & broche & catarro \\
\hline apellidarse & automovilista & broma & catástrofe \\
\hline apellido & autonomía & bromear & cate \\
\hline apelotonar & autónomo & bromista & catear \\
\hline apenar & autopista & bronca & catecismo \\
\hline apenas & autopsia & bronce & catedral \\
\hline apéndice & autor & broncear & catedrático \\
\hline apendicitis & autoridad & brotar & categoría \\
\hline aperitivo & ¡ay! & burguesía & ceder \\
\hline apero & ayer & burla & cedro \\
\hline apertura & ayo & burlar & cegar \\
\hline apestar & ayuda & burlón & ceguera \\
\hline apostar & ayudante & burrada & ceja \\
\hline apóstol & ayudar & burro & celda \\
\hline apoteosis & ayunar & buscar & celebración \\
\hline apoyar & ayunas & búsqueda & celebrar \\
\hline apoyo & ayuno & busto & célebre \\
\hline apreciable & ayuntamiento & butaca & celebridad \\
\hline apreciar & azabache & buzo & celeste \\
\hline aprecio & $a z a d a$ & buzón & celo \\
\hline apremiante & azadón & cabrón & celofán \\
\hline aprender & azafata & caca & celoso \\
\hline arandela & azafrán & cacao & célula \\
\hline $\operatorname{araña}$ & azahar & cacarear & cementerio \\
\hline arañar & azalea & cacatúa & cemento \\
\hline arañazo & azar & cacería & cena \\
\hline arar & bisonte & cacerola & cenar \\
\hline árbitro & bistec & cacharro & cencerro \\
\hline árbol & bisturí & cachear & cenicero \\
\hline arbolado & bisutería & cachete & ceniza \\
\hline arboleda & bizco & cachivache & cenizo \\
\hline arbusto & bizcocho & cacho & censo \\
\hline arca & biznieto & cachondearse & censura \\
\hline arcada & blanco & cafetera & censurar \\
\hline arcaico & blancura & cafetería & centavo \\
\hline
\end{tabular}




\begin{tabular}{|c|c|c|c|}
\hline centella & compás & despedazar & emparejar \\
\hline centellear & coronar & despedida & empatar \\
\hline centena & coronel & despedir & empate \\
\hline centenar & coronilla & despegar & empedrar \\
\hline centenario & corporal & despegue & empeine \\
\hline centeno & corpulento & despeinar & empellón \\
\hline centésimo & corral & despejado & empeñado \\
\hline centígrado & correa & despejar & empeñar \\
\hline centigramo & corrección & despellejar & empuje \\
\hline centilitro & correcto & despensa & empujón \\
\hline centimetro & corredor & despeñar & empuñar \\
\hline céntimo & corregir & desperdiciar & en \\
\hline centinela & correo & desperdicio & enamorado \\
\hline central & cuatro & desperezarse & enamorar \\
\hline cepillo & cuatrocientos & desperfecto & enano \\
\hline серо & cuba & despertador & encabezar \\
\hline cera & cubalibre & despertar & encabritarse \\
\hline cerámica & cubano & despido & encadenar \\
\hline cerca & cubeta & directo & enero \\
\hline cercanía & cubierta & director & enfadar \\
\hline cercano & cubierto & dirigente & enfado \\
\hline cercar & cubilete & dirigible & énfasis \\
\hline cerciorarse & cubito & dirigir & enfermar \\
\hline cerco & cubo & discapacitado & enfermedad \\
\hline cerda & cubrir & discernir & enfermería \\
\hline cerdo & cucaracha & disciplina & enfermero \\
\hline cereal & cuchara & discípulo & enfermo \\
\hline cerebral & cucharada & disco & enfocar \\
\hline cerebro & cucharón & discordia & enfoque \\
\hline ceremonia & cuchichear & discoteca & enfrentamiento \\
\hline ceremonioso & cuchicheo & discreción & enfrentar \\
\hline cereza & cuchilla & discreto & escarpada \\
\hline cerezo & cuchillo & discriminar & escasear \\
\hline cerilla & cuchitril & disculpa & escasez \\
\hline cero & cuclillas & disculpar & escaso \\
\hline clase & cuclillo & donde & escena \\
\hline clásico & cuco & dónde & escenario \\
\hline clasificación & cucurucho & $d o \tilde{n} a$ & escéptico \\
\hline clasificar & desorden & doping & esclavitud \\
\hline claustro & desordenado & doquier & esclavizar \\
\hline clausura & desordenar & dorado & eventual \\
\hline compadecer & desorganizar & dorar & evidencia \\
\hline compañero & desorientar & dormir & evidente \\
\hline compañia & despabilar & empanada & evitar \\
\hline comparable & despachar & empañar & evocar \\
\hline comparación & despacho & empapar & evolución \\
\hline comparar & despacio & empapelar & evolucionar \\
\hline comparativo & desparpajo & empaquetar & $e x$ \\
\hline compartir & despectivo & emparedado & exactitud \\
\hline
\end{tabular}




\begin{tabular}{|c|c|c|c|}
\hline exacto & fundición & inmaculado & legua \\
\hline exageración & fundir & interior & legumbre \\
\hline exagerado & fúnebre & interjección & lejanía \\
\hline exagerar & funeral & interlocutor & lejano \\
\hline examen & homónimo & intermediario & lejía \\
\hline examinar & homosexual & intermedio & lejos \\
\hline exclamar & hondo & interminable & lema \\
\hline exclamativo & hondureño & intermitente & lengua \\
\hline excluir & honesto & internacional & lenguado \\
\hline exclusiva & hongo & internado & litro \\
\hline exclusivo & honor & internar & lívido \\
\hline excremento & honra & inválido & llaga \\
\hline excursión & honradez & invariable & llama \\
\hline excursionista & honrado & invasión & llamada \\
\hline excusa & implicar & invasor & llamar \\
\hline exento & implorar & invencible & llamativo \\
\hline exhalación & imponente & invención & llano \\
\hline exhalar & imponer & inventar & llanta \\
\hline exhaustivo & importación & invento & llanto \\
\hline exhausto & importancia & inventor & llanura \\
\hline exhibición & importante & invernadero & llave \\
\hline exhibir & importar & invernar & llavero \\
\hline exigencia & importe & inverosímil & llegada \\
\hline exigente & imposible & inverso & llegar \\
\hline exigir & impostor & invertebrado & llenar \\
\hline formato & inalámbrico & invertir & lleno \\
\hline formidable & inalterable & itinerario & llevar \\
\hline fórmula & inanimado & izar & lobo \\
\hline formular & inaudito & izquierda & local \\
\hline forrar & inauguración & izquierdo & localidad \\
\hline forro & inaugurar & japonés & localizar \\
\hline fortalecer & incalculable & jaqueca & loco \\
\hline fortaleza & incansable & jarabe & locomotor \\
\hline fortuna & incapaz & jardín & locomotora \\
\hline forzar & incendiar & jardinera & locuaz \\
\hline fuelle & incendio & jardinería & locura \\
\hline fuente & incertidumbre & jardinero & locutor \\
\hline fuera & incesante & jarra & majestad \\
\hline fuerte & ingrediente & jarro & majestuoso \\
\hline fuerza & ingresar & jarrón & mal \\
\hline función & ingreso & jaula & malabarista \\
\hline funcionamiento & inhalar & jauría & maldad \\
\hline funcionar & inhumano & jazmín & maldecir \\
\hline funcionario & inicial & jazz & maldición \\
\hline funda & iniciar & jefatura & maldito \\
\hline fundación & iniciativa & jefe & malo \\
\hline fundamental & inicio & jengibre & maloliente \\
\hline fundamento & injusticia & jerga & malsonante \\
\hline fundar & injusto & legítimo & maltratar \\
\hline
\end{tabular}




\begin{tabular}{|c|c|c|c|}
\hline maltrecho & muleta & pamplina & pareja \\
\hline malva & muletilla & pan & parentela \\
\hline malvado & mulo & pana & parentesco \\
\hline mama & multa & panadería & paréntesis \\
\hline mamá & multar & panadero & pariente \\
\hline mamar & multinacional & panal & picudo \\
\hline mamarracho & múltiple & panameño & pie \\
\hline mamífero & nariz & pancarta & piedad \\
\hline mamporro & narración & páncreas & piedra \\
\hline mango & narrador & panda & piel \\
\hline manguera & narrar & pandilla & pienso \\
\hline manía & nasal & panera & pierna \\
\hline maniático & nata & pánico & pieza \\
\hline manicomio & natación & papel & piña \\
\hline manicura & natillas & papelera & piñata \\
\hline manifestación & nativo & papelería & piñón \\
\hline manifestante & nato & papeleta & pío \\
\hline manifestar & natural & paperas & piojo \\
\hline maniobra & naturaleza & papilla & piojoso \\
\hline maniobrar & navideño & papiro & pionero \\
\hline manipular & navío & paquete & pipa \\
\hline maniqui & neblina & par & pipi \\
\hline mímica & necesario & para & piqueta \\
\hline mimo & neceser & parábola & piragua \\
\hline mimoso & necesidad & parabrisas & pirámide \\
\hline mina & necesitado & paracaídas & platanero \\
\hline mineral & necesitar & paracaidista & plátano \\
\hline minería & necio & parachoques & plateado \\
\hline minero & nefasto & parada & platillo \\
\hline miniatura & negación & parado & platino \\
\hline minifalda & negado & paraguas & plato \\
\hline mínimo & negar & paraguayo & playa \\
\hline monitor & negativo & paragüero & plaza \\
\hline monje & orilla & paraíso & preferir \\
\hline mono & orina & paraje & prefijo \\
\hline monolito & orinal & paralelo & pregón \\
\hline monólogo & orinar & parálisis & progresista \\
\hline monosílabo & oro & paralítico & progresivo \\
\hline monótono & orquesta & paralizar & progreso \\
\hline monstruo & orquídea & parar & prohibición \\
\hline monstruoso & ortiga & pararrayos & prohibir \\
\hline montaje & ortografía & parásito & prójimo \\
\hline muestrario & ortográfico & parcela & proletario \\
\hline mugido & ortopédico & parche & prólogo \\
\hline mugir & oruga & parcial** & prolongación \\
\hline mugre & orzuelo & pardo & prolongar \\
\hline mugriento & os & parecer & promedio \\
\hline mujer & palpitar & parecido & promesa \\
\hline mulato & ратра & pared & provincia \\
\hline
\end{tabular}




\begin{tabular}{|c|c|}
\hline provinciano & salida \\
\hline provisión & saliente \\
\hline provisional & salir \\
\hline provisto & señorita \\
\hline provocar & separación \\
\hline provocativo & separar \\
\hline proximidad & sepia \\
\hline próximo & septentrional \\
\hline proyección & septiembre \\
\hline proyectar & séptimo \\
\hline proyectil & sepulcro \\
\hline proyecto & sepultar \\
\hline proyector & sepultura \\
\hline prudencia & sequedad \\
\hline prudente & sequía \\
\hline rebelión & séquito \\
\hline rebosar & ser \\
\hline rebotar & sitio \\
\hline rebote & situación \\
\hline rebozar & situar \\
\hline rebuscado & sobaco \\
\hline rebuznar & sobar \\
\hline rebuzno & soberano \\
\hline recado & soberbia \\
\hline recaer & soberbio \\
\hline recalcar & sobornar \\
\hline recalentar & sobra \\
\hline resonar & sobrar \\
\hline respaldo & $\operatorname{sog} a$ \\
\hline respectivo & sol \\
\hline respecto & solapa \\
\hline respetable & solar \\
\hline respetar & soldado \\
\hline respeto & soldar \\
\hline respetuoso & soledad \\
\hline respiración & solemne \\
\hline respirar & soler \\
\hline respiratorio & solicitar \\
\hline respiro & soltero \\
\hline rural & soltura \\
\hline ruso & solución \\
\hline rústico & solucionar \\
\hline ruta & solventar \\
\hline rutina & sombra \\
\hline salchicha & sombrero \\
\hline salchichón & sombrilla \\
\hline saldo & sombrio \\
\hline salero & someter \\
\hline saleroso & son \\
\hline
\end{tabular}

\begin{tabular}{|c|c|}
\hline suavidad & $t i$ \\
\hline suavizante & tibia \\
\hline suavizar & tibio \\
\hline subasta & tiburón \\
\hline subastar & tic \\
\hline subcampeón & tictac \\
\hline súbdito & tiempo \\
\hline subida & tienda \\
\hline subir & tierno \\
\hline súbito & tierra \\
\hline subjetivo & tieso \\
\hline subjuntivo & tiesto \\
\hline sublevar & tigre \\
\hline sublime & tijera \\
\hline sucesivo & tila \\
\hline suceso & tilde \\
\hline suciedad & timar \\
\hline sucio & timbal \\
\hline suculento & timbrazo \\
\hline sucumbir & timbre \\
\hline sucursal & tímido \\
\hline sudadera & timo \\
\hline sudar & timón \\
\hline sudeste & timonel \\
\hline sudoeste & timpano \\
\hline sudor & tirón \\
\hline suprimir & tirotear \\
\hline supuesto & tiroteo \\
\hline sur & titere \\
\hline surcar & titiritero \\
\hline surco & titubear \\
\hline sureste & titubeo \\
\hline surgir & titular \\
\hline suroeste & título \\
\hline surtido & tiza \\
\hline surtidor & toalla \\
\hline surtir & vidrio \\
\hline susceptible & viejo \\
\hline suspender & viento \\
\hline temporada & vientre \\
\hline temporal & viernes \\
\hline temprano & viga \\
\hline tenaz & vigente \\
\hline tenaza & vigilancia \\
\hline tendedero & vigilante \\
\hline tendencia & vigilar \\
\hline tender & villa \\
\hline textura & villancico \\
\hline tez & villano \\
\hline
\end{tabular}


vitamina

vitrina

viudo

víveres vivero

vivienda

vivíparo

vivir $x$

xenofobia

xenófobo

xilófono

ANEXO 5

VOCABLOS DE DIME ENCONTRADOS EN ANAYA

\begin{tabular}{|c|c|c|c|}
\hline ablandar & acción & agobio & amargar \\
\hline abochornar & accionar & agonía & analfabeta \\
\hline abofetear & acechar & aldea & analfabeto \\
\hline abogado & aceite & aldeano & analgésico \\
\hline abolición & aceitero & alegar & análisis \\
\hline abolir & aceitoso & alegrar & analizar \\
\hline abolladura & aceituna & alegre & analogía \\
\hline abollar & aceleración & alegría & anaranjado \\
\hline abominable & acelerador & alejar & anarquía \\
\hline abonar & acelerar & alemán & anatomía \\
\hline abono & adjudicar & alergia & anca \\
\hline abordaje & administración & alero & ancho \\
\hline aborigen & administrador & alerta & anchoa \\
\hline aborrecer & administrar & aleta & anchura \\
\hline abortar & admirable & aletargar & anciano \\
\hline aborto & admiración & aletear & ancla \\
\hline abotonar & admirador & alevosía & anclar \\
\hline acá & admirar & aludir & andamio \\
\hline acabado & admitir & alumbrado & andar \\
\hline acabar & adobe & alumbrar & añicos \\
\hline acacia & adolescencia & aluminio & añil \\
\hline academia & adolescente & alumno & año \\
\hline acalambrarse & adonde & alunizaje & aorta \\
\hline acalorarse & adónde & alunizar & apacible \\
\hline acampar & adoptar & alusión & apaciguar \\
\hline acantilado & adoptivo & aluvión & apadrinar \\
\hline acariciar & agarrar & alza & apagado \\
\hline acaso & agarrotarse & alzar & apagar \\
\hline acatar & agencia & amabilidad & apagón \\
\hline acatarrarse & agente & amable & apalabrar \\
\hline acceder & ágil & amamantar & apalear \\
\hline accesible & agilidad & amanecer & aparador \\
\hline acceso & agilizar & amanerado & auditivo \\
\hline accesorio & agitar & amansar & auditorio \\
\hline accidentado & aglomeración & amante & auge \\
\hline accidente & agobiar & amar & augurar \\
\hline
\end{tabular}




\begin{tabular}{|c|c|c|c|}
\hline augurio & avellana & biznieto & catedral \\
\hline aula & avellano & blancura & catedrático \\
\hline aullar & avena & blando & categoría \\
\hline aullido & avenida & blanquear & catolicismo \\
\hline aumentar & aventajado & blanquecino & católico \\
\hline aumentativo & aventajar & blasfemar & catorce \\
\hline aumento & aventura & blasfemia & caucho \\
\hline aun & avería & blindar & caudal \\
\hline aún & averiar & bloc & caudaloso \\
\hline aunque & averiguar & bloque & causa \\
\hline aureola & avestruz & bloquear & causar \\
\hline aurora & baldosa & blusa & chofer \\
\hline ausencia & ballena & bollo & chopo \\
\hline ausentarse & ballenato & bomba & choque \\
\hline ausente & ballet & bombacho & chorizo \\
\hline austeridad & balneario & bombardear & chorlito \\
\hline austero & balón & bombardeo & chorro \\
\hline australiano & balonazo & bombero & choza \\
\hline auténtico & baloncesto & bombilla & chubasco \\
\hline auto & balsa & bombo & chuchería \\
\hline autobiografia & bálsamo & bombón & chulada \\
\hline autobús & banana & bonachón & chuleta \\
\hline autógrafo & banco & bondad & chupado \\
\hline autómata & berenjena & bondadoso & chupar \\
\hline automático & bermellón & bonito & chupetón \\
\hline automatizar & bermudas & candidato & chupón \\
\hline automóvil & berrear & candidatura & churrería \\
\hline automovilismo & berrido & cándido & churrero \\
\hline automovilista & berrinche & candil & churro \\
\hline autonomía & berro & candor & chutar \\
\hline autónomo & besar & canela & cicatriz \\
\hline autopista & beso & cangrejo & cicatrizar \\
\hline autopsia & bestia & canguro & ciclismo \\
\hline autor & bestial & caníbal & ciclista \\
\hline autoridad & bestialidad & canica & ciclo \\
\hline autoritario & besucón & canijo & ciclón \\
\hline autorización & betún & canino & ciego \\
\hline autorizar & biberón & canjear & cielo \\
\hline auxiliar & bibliografía & cano & coeficiente \\
\hline aval & biblioteca & canoa & cofre \\
\hline avalancha & bibliotecario & cansancio & coger \\
\hline avance & bicarbonato & cansar & cogollo \\
\hline avanzar & bicho & cantar & cogote \\
\hline avaricia & bici & catálogo & coherencia \\
\hline avaro & bicicleta & catar & coherente \\
\hline avasallar & bicolor & catarata & cohete \\
\hline avatares & bisutería & catástrofe & coincidencia \\
\hline ave & bizco & catear & coincidir \\
\hline avecinarse & bizcocho & catecismo & cojear \\
\hline
\end{tabular}




\begin{tabular}{|c|c|c|c|}
\hline cojera & común & cúspide & dibujante \\
\hline cojin & comunicación & custodiar & dibujar \\
\hline cojo & comunicar & cutis & dibujo \\
\hline cojón & comunidad & cuyo & dicha \\
\hline collar & comunión & delatar & dicho \\
\hline colorido & comunismo & delegado & dichoso \\
\hline colosal & con & delegar & diciembre \\
\hline columna & coronar & deletrear & dictado \\
\hline columpiar & coronilla & delfin & dictador \\
\hline coma & corporal & delgadez & dictadura \\
\hline comadreja & corpulento & delgado & dictar \\
\hline comadrona & corral & deliberar & didáctico \\
\hline comandante & correa & delicadeza & disimulo \\
\hline comando & corrección & delicia & disipar \\
\hline combate & correcto & delicioso & dislocar \\
\hline combatir & corredor & delimitar & disolvente \\
\hline combinar & correo & delincuencia & disolver \\
\hline combustible & correr & delincuente & disparar \\
\hline combustión & correspondencia & delirar & disparatado \\
\hline comedia & corresponder & delito & disparate \\
\hline comediante & correspondiente & desabrochar & disparo \\
\hline comedor & corresponsal & desafiar & disponer \\
\hline comentar & corriente & desafinar & disponible \\
\hline comentario & corrillo & desafio & enemistar \\
\hline comenzar & corro & desagradecido & energía \\
\hline comer & corrupción & desagüe & enérgico \\
\hline comerciante & corsario & desaliento & energúmeno \\
\hline comerciar & cortada & desangrarse & enero \\
\hline comercio & cortar & desanimar & enfadarse \\
\hline comestible & cuchillo & desánimo & enfado \\
\hline cometa & cuchitril & desaparecer & énfasis \\
\hline cometer & cuclillas & desinteresado & enfermar \\
\hline cometido & cuclillo & deslizar & enfermedad \\
\hline cómico & сисо & deslumbrante & enfermería \\
\hline comida & cucurucho & deslumbrar & enfermero \\
\hline comienzo & cuello & desmayarse & enfermo \\
\hline comillas & cuenta & desmejorado & enfrentamiento \\
\hline comilona & cuentagotas & desmemoriado & enfrentar \\
\hline comino & curativo & desmenuzar & enfrente \\
\hline comisaría & curiosear & desmontable & enfriar \\
\hline comisario & curiosidad & desmontar & enfundar \\
\hline comisión & curioso & desnivel & enfurecer \\
\hline comité & cursi & desnudar & enfurruñarse \\
\hline comitiva & cursillo & desnudo & engalanar \\
\hline como & cursiva & desobedecer & enganchar \\
\hline compuesto & curso & diana & enganche \\
\hline computadora & cursor & diapositiva & engañar \\
\hline cómputo & curtir & diario & época \\
\hline comulgar & curvo & diarrea & equilibrado \\
\hline
\end{tabular}




\begin{tabular}{|c|c|c|c|}
\hline equilibrar & fugitivo & guardería & mafia \\
\hline equilibrio & fulano & guardia & magia \\
\hline equilibrista & gracioso & guardián & mágico \\
\hline equipaje & gradería & guarecer & magisterio \\
\hline equipo & grado & guarida & magnate \\
\hline equis & gradual & guarnición & magnifico \\
\hline equitación & graduar & guasa & magnitud \\
\hline equivalente & grafia & guasón & mago \\
\hline equivaler & gráfico & guatemalteco & magullar \\
\hline equivocación & gragea & guateque & maíz \\
\hline equivocarse & gramatical & guerra & $\operatorname{maña}$ \\
\hline era & gramo & guerrero & mañana \\
\hline erguir & gran & guiso & mañanero \\
\hline erizar & granada & guitarra & mañoso \\
\hline erizo & graznar & guitarrista & mapa \\
\hline estación & graznido & gustar & maqueta \\
\hline estacionamiento & gremio & gusto & maquillador \\
\hline estacionar & greña & homónimo & maquillaje \\
\hline estadio & griego & hondo & maquillar \\
\hline estadistica & grieta & hondureño & máquina \\
\hline estado & grifo & honesto & maquinaria \\
\hline estadounidense & grillo & hongo & maquinista \\
\hline estafa & gripe & honor & mar \\
\hline estalagmita & grisáceo & honra & maraca \\
\hline estallar & gritar & honradez & maratón \\
\hline estallido & griterío & honrado & medieval \\
\hline estambre & grito & hora & medio \\
\hline estampado & grosella & horario & mediocre \\
\hline estancar & grosería & incómodo & mediodía \\
\hline forma & grosero & incomparable & medir \\
\hline formación & grosor & incompleto & meditación \\
\hline formalidad & grúa & incomprensión & meditar \\
\hline formar & grueso & inconfundible & mediterráneo \\
\hline formato & grulla & inconsciente & medusa \\
\hline formidable & grumo & incontable & megáfono \\
\hline fórmula & gruñido & inconveniente & mejilla \\
\hline formular & gruñir & incorporar & mejillón \\
\hline forrar & gruñón & incorrección & mejor \\
\hline forro & grupo & incorrecto & molécula \\
\hline fortalecer & gruta & incrédulo & moler \\
\hline fortaleza & guadaña & increíble & molestia \\
\hline fortuna & guante & incrementar & molinero \\
\hline fuelle & guantera & incrustar & molinillo \\
\hline fuera & guapo & incubadora & molino \\
\hline fuerte & guardabosque & incubar & molusco \\
\hline fuerza & guardaespaldas & inculto & momentáneo \\
\hline fuga & guardameta & maduro & momento \\
\hline fugarse & guardar & maestría & morsa \\
\hline fugaz & guardarropa & maestro & morse \\
\hline
\end{tabular}




\begin{tabular}{|c|c|c|c|}
\hline mortal & ola & relámpago & sofisticado \\
\hline mortífero & jole! & relampaguear & sofocante \\
\hline mosaico & óleo & relatar & sofocar \\
\hline mosca & oleoducto & relativo & $\operatorname{sog} a$ \\
\hline moscardón & oler & relato & sol \\
\hline mosquear & olfatear & relevante & temperamento \\
\hline mosquito & olfato & relevar & temperatura \\
\hline mostaza & olimpiada & relevo & tempestad \\
\hline mosto & olimpico & relieve & tempestuoso \\
\hline mostrador & olivar & religioso & templado \\
\hline munición & olivo & relinchar & templar \\
\hline muñeca & olla & relincho & temple \\
\hline muñequera & olmo & reliquia & temporada \\
\hline mural & olor & rellano & temporal \\
\hline muralla & oloroso & retirado & temprano \\
\hline murciélago & olvidar & retirar & tenaz \\
\hline murmullo & olvido & retiro & tendedero \\
\hline muro & partitura & reto & tendencia \\
\hline musa & parto & retocar & textura \\
\hline musaraña & párvulo & retoque & tibio \\
\hline muscular & pasa & retorcer & tiburón \\
\hline músculo & pasable & retornar & tic \\
\hline musculoso & pasada & retransmisión & tictac \\
\hline museo & pasadizo & retransmitir & tiempo \\
\hline musgo & pasado & retrasar & tienda \\
\hline musical & pasador & retraso & tierno \\
\hline obús & pasaje & retratar & tierra \\
\hline obvio & pasajero & retrato & tieso \\
\hline oca & pasamanos & rumiar & tiesto \\
\hline ocasión & pasamontañas & rumor & tigra \\
\hline ocasionar & pasaporte & rupestre & tigre \\
\hline ocaso & pasar & rural & tijeras \\
\hline occidente & redactar & ruso & tila \\
\hline oceánico & redactor & rústico & veranear \\
\hline océano & redada & ruta & veraniego \\
\hline ochenta & redil & rutina & verano \\
\hline ocho & redoblar & socavón & verbena \\
\hline ochocientos & redondear & sociable & verdad \\
\hline ocio & redondel & social & verde \\
\hline ocioso & redondo & socialismo & verdoso \\
\hline ocre & reducción & sociedad & verdugo \\
\hline octavo & reducido & socio & verdulería \\
\hline octubre & referencia & socorrer & verdura \\
\hline ocular & referir & socorrista & vergonzoso \\
\hline oculista & relación & socorro & vergüenza \\
\hline ocultar & relacionar & sofá & verdadero \\
\hline
\end{tabular}

